Article

\title{
Rheological Properties and Flow Behaviour of Cement-Based Materials Modified by Carbon Nanotubes and Plasticising Admixtures
}

\author{
Gintautas Skripkiunas ${ }^{1, *(\mathbb{D})}$, Ekaterina Karpova ${ }^{1}$, Joana Bendoraitiene ${ }^{2}$ and \\ Irmantas Barauskas ${ }^{3}$ (D) \\ 1 Department of Building Materials and Fire Safety, Vilnius Gediminas Technical University, Sauletekio al. 11, \\ LT-10223 Vilnius, Lithuania; ekaterina.karpova@vgtu.lt \\ 2 Department of Polymer Chemistry and Technology, Kaunas University of Technology, K. Donelaicio g. 73, \\ LT-44249 Kaunas, Lithuania; joana.bendoraitiene@ktu.lt \\ 3 Department of Silicate Technology, Kaunas University of Technology, K. Donelaicio g. 73, \\ LT-44249 Kaunas, Lithuania; irmantas.barauskas@ktu.lt \\ * Correspondence: gintautas.skripkiunas@vgtu.lt
}

Received: 9 September 2020; Accepted: 22 September 2020; Published: 29 September 2020

check for updates

\begin{abstract}
In this study, the rheological properties of cement paste modified by a suspension containing both multi-walled carbon nanotubes (MWCNT) and carboxymethyl cellulose (CMC) (MWCNT/CMC suspension) with different types of plasticising admixtures (Pl), such as lignosulphonate (LS), sulfonated naphthalene formaldehyde condensate (NF), and polycarboxylate ether (PCE) were evaluated. The increase in yield stress and plastic viscosity up to $20 \%$ was established in the case of the modification of cement-based mixtures by MWCNT in the dosage up to $0.24 \%$ by weight of cement (bwoc) without Pl and with LS and NF. The complex modification of cement paste by MWCNT and PCE increases the yield stress and plastic viscosity from the MWCNT dosage of $0.06 \%$ and $0.015 \%$ bwoc, respectively. The yield stress and plastic viscosity of cement paste with PCE enhanced by $265 \%$ and $107 \%$, respectively, in a MWCNT dosage of $0.12 \%$ bwoc. MWCNT do not have a significant influence on the flow behaviour index of cement paste; however, in the case of usage of PCE, the shear thickening effect decreased from a MWCNT dosage of $0.03 \%$ bwoc. The significant reduction in the volume coefficient of water bleeding by 99,100 , and $83 \%$ was obtained with LS, NF, and PCE, respectively, with an increase in MWCNT dosage up to $0.24 \%$ bwoc.
\end{abstract}

Keywords: cement paste; carbon nanotubes; plasticising admixture; rheology; rotational rheometer; Herschel-Bulkley model; flow behaviour; yield stress; plastic viscosity; water bleeding

\section{Introduction}

The growth of demand for concrete structures of different functionality requires the development of new concrete compositions and innovative concrete technologies of transportation, handling, pumping, and compacting with a decrease in economic expenses. The development of pumping technology and the design of self-compacting concrete (SCC) are one of the crucial topics in modern concrete technology [1-5]. A number of research works demonstrate the necessity to investigate the rheological properties of concrete in addition to evaluation of workability. The correlation between the rheological and technological parameters of concrete mixtures is necessary for the improvement of concrete technologies and production of concrete with high workability and high performance [6-8]. The understanding of the rheology of cement-based materials and its correlation with the technological characteristics of concrete determines the properties of concrete in a hardened state [9] and its durability. 
The rheological properties are important for the surface quality of concrete structures and its application for architectural concrete as well.

The liquid phase of the cement system can be modified by the introduction of nanoparticles, which significantly increases the surface area of the solid phase and causes changes in the surface tension and zeta potential. The small size and, as a consequence, the high surface area can be the factors which explain the changes in the rheology of cement systems with nanoadditives [10]. For instance, Shang et al. [11] studied the effect of graphene oxide on yield stress and plastic viscosity and established their increase with higher graphene oxide dosages. Kawashima et al. [12] observed a stiffening effect in cement paste modified by nanoclays. The impact of nano- $\mathrm{TiO}_{2}$ and nano- $\mathrm{SiO}_{2}$ on the cement paste rheology was evaluated by Li et al. [13] and Senff et al. [14], respectively. The research established the increase in yield and plastic viscosity of cement paste.

Considerable interest is concentrated on the modification of cement composites by carbon nanotubes (CNTs) due to its outstanding properties $[15,16]$. The number of research works on the impact of CNTs on cement-based materials in a fresh state is insufficient [17], opposite to the studies devoted to the improvement of mechanical properties and microstructure of cement composites with the addition of CNTs $[18,19]$. The flowability tests were implemented to study the effect of CNTs on the cement paste and mortar in a fresh state [20,21]. Collins et al. [20] performed the mini-slump test for ordinary cement pastes modified by different dosages of CNTs. The spreading diameter of cement paste was decreased by $14.5 \%$ with the addition of $0.5 \%$ by weight of cement (bwoc) of CNTs at a water to cement $(\mathrm{w} / \mathrm{c})$ ratio of 0.5 . Other dosages of $\mathrm{CNTs}$ and other $\mathrm{w} / \mathrm{c}$ ratios showed the decrease in flowability of cement pastes as well. Konsta-Gdoutos et al. [21] observed that pristine CNTs with different aspect ratios in the dosage of $0.1 \%$ bwoc lead to a decrease in flowability from 22.1 to $18.6 \mathrm{~cm}$.

In addition to flowability tests, it is necessary to provide rheological investigations to obtain, more deeply, an understanding of the action mechanisms of nanoadditives in cement systems. Some attempts to study the rheology of nanomodified cement pastes by the use of rheometers and rheological models were made [10,22-29]. Ma et al. [22] established an increase in yield stress and plastic viscosity of cement mortar modified by CNTs. Jiang et al. [10] and Skripkiunas et al. [27-29] observed an increase in yield stress and plastic viscosity of nanomodified cement paste as well. Opposite to these research works, Souza et al. [23] and Paula et al. [24] did not obtain any changes in rheology of the cement pastes and slurries prepared with CNTs synthesised on cement clinker. The differences in obtained results can be linked with the composition of cement systems, type of CNTs, dispersing agents, applied rheological models, and other factors. Reales et al. [25] and Nadiv et al. [26] highlighted the relevance of an applied dispersing agent and its impact on the rheology of cement systems.

The suspension of nanoparticles is often homogenised with the application of different types of plasticising admixtures $(\mathrm{Pl})$ used in concrete technology. $\mathrm{Pl}$ is an indispensable component of modern concrete, which manages the properties of concrete in a fresh state due to its plasticising effect. The lignosulphonate (LS), sulfonated naphthalene formaldehyde condensate (NF), polycarboxylate ether (PCE), and acrylic polymer plasticisers are one of the most widely used Pl nowadays $[30,31]$. The plasticising efficiency of $\mathrm{Pl}$ in cement systems mainly depends on adsorption processes on the cement particles' surface (surface tension of liquid phase on cement particles) [32,33], zeta potential [34,35], which is defined by the properties of used cement, and $\mathrm{Pl}[31,36]$. Cement suspension stability with $\mathrm{Pl}$ is controlled by the balance of attractive and repulsive forces, which depends on the steric or electrostatic action mechanism of applied Pl. The various molecular structures of Pl cause the distinction in action mechanisms [37].

The dispersing effect of LS consists of electrostatic repulsion between the cement particles when negatively charged functional groups of LS adsorb on the cement particles. This adsorption leads to giving the negative charge to cement particles and the appearance of electrostatic repulsion between them $[32,38]$. 
NF possess a higher water reduction capability up to $30 \%$ in comparison with LS. The action mechanism of NF is based on electrostatic and steric repulsive forces with more pronounced electrostatic effects $[37,39]$.

PCE with a comb-shaped structure has a higher plasticising efficiency in comparison with LS and NF. The combination of electrostatic and steric effects underlies the action mechanism of this plasticiser in cement systems, which makes it more efficient in comparison with others [40-42].

The changes in molecular structure of $\mathrm{Pl}$ provide the improvement of their plasticising efficiency. Nowadays, there are a significant number of research works on the synthesis of $\mathrm{Pl}$ with new molecular architecture, which contributes to the changes in rheological and technological properties of cement-based materials [43-47].

The complex admixture based on $\mathrm{Pl}$ and nanoparticles can improve the plasticising efficiency of Pl. Application of $\mathrm{Pl}$ in high dosages can lead to the occurrence of water bleeding when gravity dominates the colloidal forces between cement particles in low viscosity liquid phase [48,49]. Particularly, this issue can be present in the production of SCC. The usage of nanoparticles, with their high surface area, can allow controlling of the bleeding of plasticised concrete mixtures [50].

The literature review findings showed that there are not enough research workson the rheology of cement-based materials modified by CNTs. The action mechanisms of CNTs separately and in combination with $\mathrm{Pl}$ in a fresh cement paste are not clear and require further investigation. Besides, the selection of a suitable rheological model for cement-based materials with CNTs is also relevant.

The current research is focused on the investigation of the rheological properties of cement pastes modified by suspension containing both multi-walled carbon nanotubes and carboxymethyl cellulose (MWCNT/CMC suspension) without Pl and with LS, NF, and PCE. The main rheological parameters, such as yield stress, plastic viscosity, and shear thinning/thickening (flow behaviour) indexes were evaluated depending on the MWCNT dosage and type of Pl based on the Herschel-Bulkley rheological model. Water bleeding of nanomodified cement paste was observed in the course of the research as well. The understanding of rheological behaviour of the plasticised cement paste with MWCNT can be valuable for further design of complex admixtures based on MWCNT and Pl. The present research is a continuation of research works [27-29], which generalise the research data on the rheological properties and water bleeding of cement pastes modified by MWCNT/CMC suspension in the presence of three different $\mathrm{Pl}$, with application of the Herschel-Bulkley model for approximation of the experimental data; a possible explanation of the action mechanisms of MWCNT in the plasticised cement pastes is also proposed.

\section{Experimental Study}

\subsection{Materials}

Portland cement without mineral additives CEM I $42.5 \mathrm{R}$ and with fineness by Blain of $3552 \mathrm{~cm}^{2} / \mathrm{g}$, as a more widely used cement in construction practice, was used as a binder. The mineral composition and physical and mechanical properties of the applied cement are presented in the research [27].

The LS, NF, and PCE were taken as a surfactant to homogenise the nanotubes in the volume of the aqueous suspension and into the cement systems. The characteristics of $\mathrm{Pl}$ are listed in Table 1 . The chemical structures of applied $\mathrm{Pl}$ are presented in Figure 1a-c. 
Table 1. Properties of plasticising admixtures.

\begin{tabular}{cccc}
\hline Characteristic & Lignosulphonate(LS) & $\begin{array}{c}\text { Naphthalene } \\
\text { Formaldehyde (NF) }\end{array}$ & $\begin{array}{c}\text { Polycarboxylate Ether } \\
\text { (PCE) }\end{array}$ \\
\hline Form & liquid & liquid & liquid \\
Colour & dark brown & yellow & yellow \\
Dry content, $\%$ & $30-40$ & $40-50$ & 50 \\
Specific gravity, g/cm & 1.14 & 1.20 & 1.10 \\
pH & $4-6$ & $7-9.5$ & 4 \\
Recommended dosage, $\%$ & $0.4-1.2$ & $0.5-2.0$ & $0.2-2.0$ \\
\hline
\end{tabular}
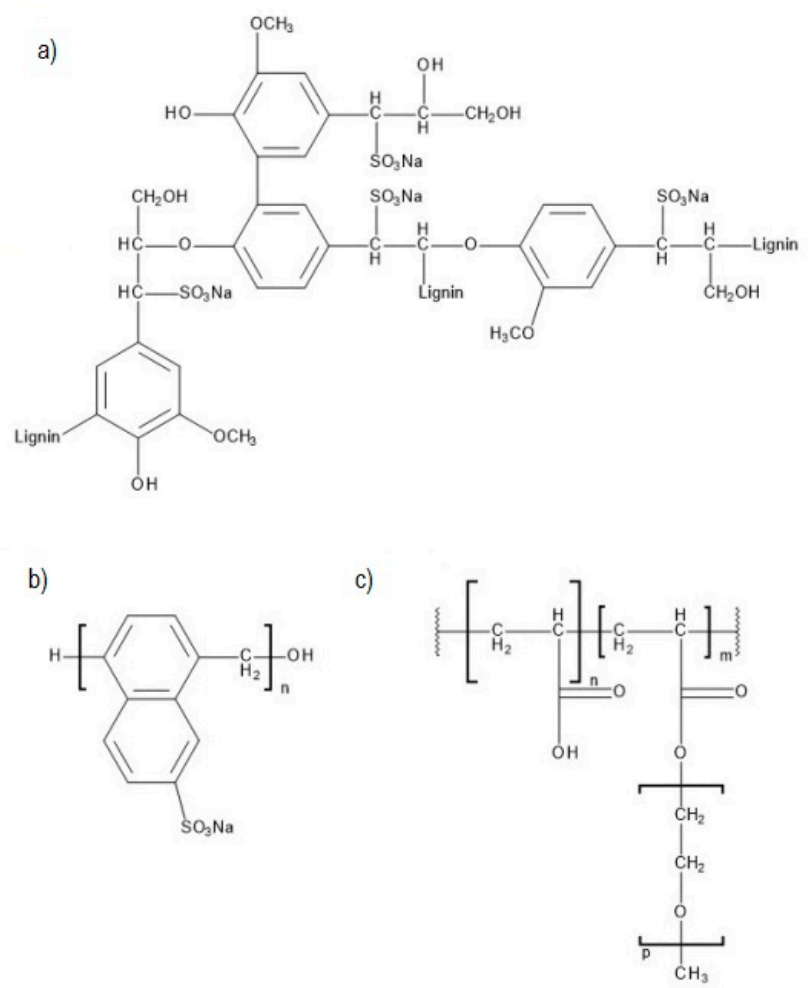

Figure 1. Chemical structures of lignosulphonate (LS) (a), naphthalene formaldehyde (NF) (b), and polycarboxylate ether (PCE) (c) plasticisers [51].

The masterbatch pellets "Graphistrength CW 2-45" ("Arkema", Colombo, France), consisting of $45 \mathrm{wt} \%$ of MWCNT and $55 \mathrm{wt} \%$ of carboxymethyl cellulose (CMC), were used for the homogenisation of MWCNT suspension. The pellets were immersed in distilled water preheated up to $75^{\circ} \mathrm{C}$. MWCNT have a diameter of 15-20 $\mathrm{nm}$ and length of $0.1-10 \mu \mathrm{m}$.

The Scanning Electron Microscopy (SEM) image of the dried MWCNT/CMC suspension with content of MWCNT and CMC at $1 \%$ and $1.22 \%$, respectively, presented in Figure 2, identifies the feature of MWCNT to form bundles with diameters of about $200 \mathrm{~nm}$. 


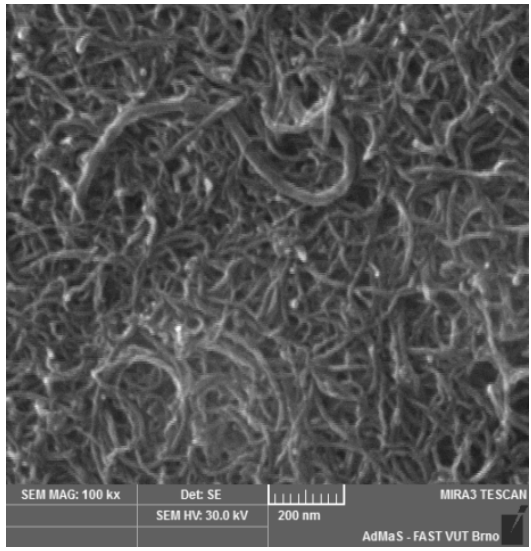

Figure 2. The Scanning Electron Microscopy image of dried suspension containing multi-walled carbon nanotubes and carboxymethyl cellulose (MWCNT/CMC suspension).

\subsection{Testing Methodology}

The homogenisation of the MWCNT/CMC suspension was carried out for $6 \mathrm{~min}$ by ultrasonic homogeniser Bandelin Sonopuls HD $3400(400 \mathrm{~W}, 20 \mathrm{kHz})$. The optimisation of the applied homogenisation processes was studied and described in the research works [27,28].

Four types of MWCNT/CMC suspensions with various MWCNT dosages were homogenised, such as MWCNT/CMC suspensions without Pl, with LS, NF, and PCE. MWCNT dosage was varied from 0 to $0.96 \%$ in the aqueous suspension. Dosage of $\mathrm{Pl}$ was of $3.8 \%$ ( $1 \%$ bwoc of cement) in all MWCNT/CMC suspensions. The ratio between Pl and MWCNT varied from 4 to 256 .

The mix design of MWCNT/CMC suspension with and without Pl homogenised by the ultrasonication method is presented in Table 2. Table 2 includes the amount of CMC in the volume of suspension due to the fact that pellets "Graphistrength CW 2-45" consisted of MWCNT and CMC (see the previous section).

Table 2. Composition of suspension containing multi-walled carbon nanotubes and carboxymethyl cellulose (MWCNT/CMC suspension) with and without plasticising admixtures (Pl) homogenised by ultrasonication method.

\begin{tabular}{|c|c|c|c|c|c|c|c|}
\hline \multirow[b]{2}{*}{ Designation } & \multicolumn{2}{|c|}{$\begin{array}{c}\text { MWCNT/CMC Suspension } \\
\text { without Pl }\end{array}$} & \multirow[b]{2}{*}{ Designation } & \multicolumn{3}{|c|}{ MWCNT/CMC Suspension with Pl } & \multirow{2}{*}{$\begin{array}{c}\text { Time of } \\
\text { Ultrasonication, } \\
\text { min }\end{array}$} \\
\hline & $\begin{array}{c}\text { MWCNT in } \\
\text { Volume of } \\
\text { Suspension, \% }\end{array}$ & $\begin{array}{l}\text { CMC in the } \\
\text { Volume of } \\
\text { Suspension, \% }\end{array}$ & & $\begin{array}{c}\text { MWCNT in } \\
\text { Volume of } \\
\text { Suspension, \% }\end{array}$ & $\begin{array}{c}\text { CMC in the } \\
\text { Volume of } \\
\text { Suspension, \% }\end{array}$ & $\begin{array}{l}\text { Pl in Volume of } \\
\text { Suspension, \% }\end{array}$ & \\
\hline S15 & 0.015 & 0.018 & SP15 & 0.015 & 0.018 & & \\
\hline S30 & 0.030 & 0.037 & SP30 & 0.030 & 0.037 & & \\
\hline S60 & 0.060 & 0.073 & SP60 & 0.060 & 0.073 & & \\
\hline $\mathrm{S} 120$ & 0.120 & 0.146 & SP120 & 0.120 & 0.146 & 3.8 & 6 \\
\hline S240 & 0.240 & 0.293 & SP240 & 0.240 & 0.293 & & \\
\hline S480 & 0.480 & 0.586 & SP480 & 0.480 & 0.586 & & \\
\hline S960 & 0.960 & 1.171 & SP960 & 0.960 & 1.171 & & \\
\hline
\end{tabular}

The particle size analysis and zeta potential measurements for MWCNT/CMC suspension after homogenisation were carried out by particle size and zeta potential analyser DelsaNano $C$ from Beckman Coulter [28].

Rotational rheometer Rheotest RN 4.1 with coaxial cylinders was applied for the rheological test. The rheological test was performed at 5, 60, and 120 min after cement paste mixing according to the mode presented by [29]. The mix design of the cement pastes for the rheological test is presented in Tables 3 and 4 . 
Table 3. Mix design of the cement pastes for rheological test (without Pl).

\begin{tabular}{ccccccc}
\hline Designation & Cement, $\mathbf{g}$ & W/C & Water, g & $\begin{array}{c}\text { MWCNT/CMC } \\
\text { Suspension, }\end{array}$ & $\begin{array}{c}\text { MWCNT, \% } \\
\text { bwoc }\end{array}$ & $\begin{array}{c}\text { CMC, \% } \\
\text { bwoc }\end{array}$ \\
\hline C0 & 200 & 0.30 & 60 & 0 & 0 & 0 \\
C4 & 200 & 0.30 & 0 & 60 & 0.00375 & 0.00460 \\
C8 & 200 & 0.30 & 0 & 60 & 0.0075 & 0.0092 \\
C15 & 200 & 0.30 & 0 & 60 & 0.015 & 0.018 \\
C30 & 200 & 0.30 & 0 & 60 & 0.030 & 0.037 \\
C60 & 200 & 0.30 & 0 & 60 & 0.060 & 0.073 \\
C120 & 200 & 0.30 & 0 & 60 & 0.120 & 0.146 \\
C240 & 200 & 0.30 & 0 & 60 & 0.240 & 0.293 \\
\hline
\end{tabular}

Table 4. Mix design of the cement pastes for rheological test (with Pl).

\begin{tabular}{cccccccc}
\hline Designation Cement, & W/C & Water, g & $\begin{array}{c}\text { Pl, \% } \\
\text { bwoc }\end{array}$ & $\begin{array}{c}\text { MWCNT/CMC } \\
\text { Suspension with } \\
\text { Pl, g }\end{array}$ & $\begin{array}{c}\text { MWCNT, } \\
\text { \% bwoc }\end{array}$ & $\begin{array}{c}\text { CMC, \% } \\
\text { bwoc }\end{array}$ \\
\hline CP0 & 200 & 0.25 & 50 & 1 & 0 & 0 & 0 \\
CP4 & 200 & 0.25 & 0 & 1 & 50 & 0.00375 & 0.00460 \\
CP8 & 200 & 0.25 & 0 & 1 & 50 & 0.0075 & 0.0092 \\
CP15 & 200 & 0.25 & 0 & 1 & 50 & 0.015 & 0.018 \\
CP30 & 200 & 0.25 & 0 & 1 & 50 & 0.030 & 0.037 \\
CP60 & 200 & 0.25 & 0 & 1 & 50 & 0.060 & 0.073 \\
CP120 & 200 & 0.25 & 0 & 1 & 50 & 0.120 & 0.146 \\
CP240 & 200 & 0.25 & 0 & 1 & 50 & 0.240 & 0.293 \\
\hline
\end{tabular}

The scheme of homogenisation of the MWCNT/CMC suspension and cement paste modification by the MWCNT/CMC suspension is represented in Figure 3.

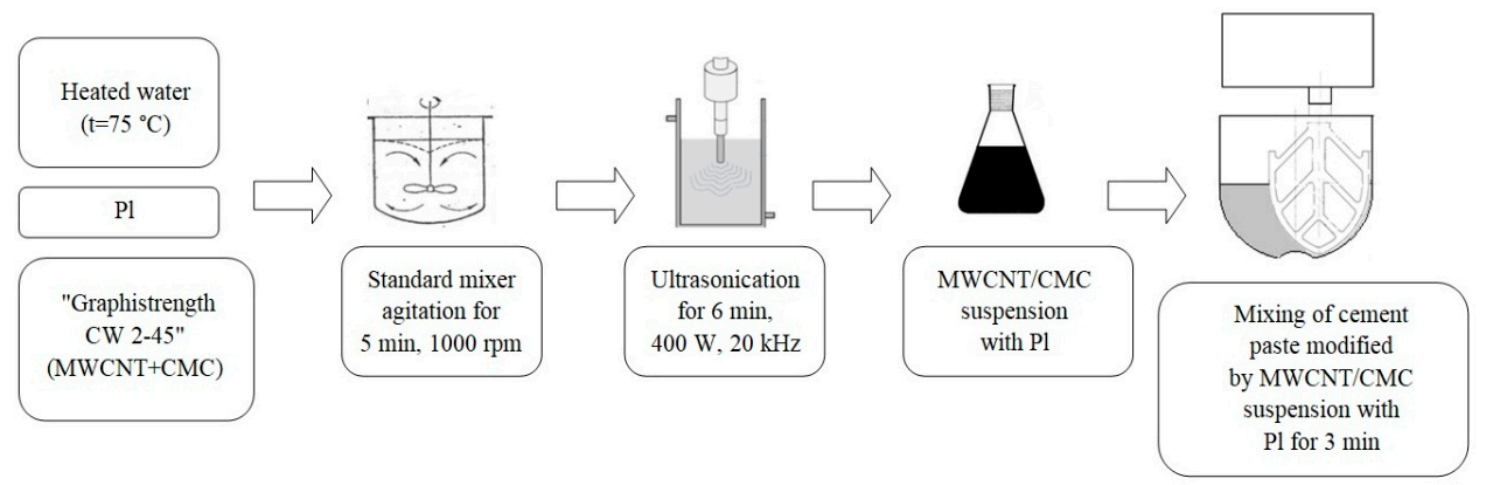

Figure 3. Modification of cement paste by MWCNT/CMC suspension.

The yield stress $\left(\tau_{0}\right)$ and plastic viscosity $(\mu)$ were obtained in the course of approximation of the flow curve by means of the Herschel-Bulkley model expressed by equation:

$$
\tau=\tau_{0}+\mu \cdot \dot{\gamma}^{n}
$$

where $\tau$ is shear stress, $\mathrm{Pa} ; \tau_{0}$ is yield stress of the cement paste, $\mathrm{Pa} ; \mu$ is plastic viscosity, $\mathrm{Pa} \cdot \mathrm{s} ; \dot{\gamma}$ is shear rate, $\mathrm{s}^{-1} ; n$ is shear thinning or shear thickening (flow behaviour) index if $n<1$ or $n>$ 1 , respectively [28,51]. Figure 4 presents an example of the approximation of experimental points according to the Herschel-Bulkley model. 


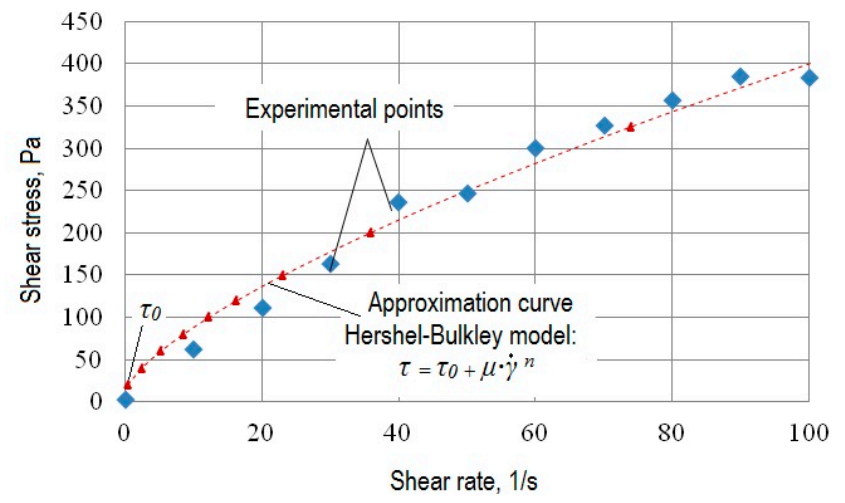

Figure 4. Approximation of experimental flow curve by Herschel-Bulkley model.

For the water bleeding test, the cement and the MWCNT/CMC suspension with a ratio of 1:1 were put into a $200 \mathrm{~mL}$ plastic container and mixed for $4 \mathrm{~min}$. The plastic container was left to stand without moving for $2 \mathrm{~h}$. After $2 \mathrm{~h}$ since the beginning of the test, the bleeding water was collected from the surface of sedimented cement by the syringe.

The coefficient of the water bleeding was expressed by the equation:

$$
K_{b}=\frac{a-b}{a} \cdot 100 \%
$$

where $K_{b}$ is the coefficient of water bleeding, \%; $a$ is an initial volume of cement paste, $\mathrm{cm}^{3} ; b$ is the volume of sedimented cement, $\mathrm{cm}^{3}[28]$.

\section{Experimental Results}

3.1. Characteristics of Suspension Containing Multi-Walled Carbon Nanotubes and Carboxymethyl Cellulose

The MWCNT/CMC suspension with various Pl has differences in average particle size. As is seen in Figure 5, LS and NF slightly decrease the average particle size in the suspension in comparison with the MWCNT/CMC suspension with PCE. The minimum diameters of about 220 and $240 \mathrm{~nm}$ were observed for the MWCNT suspension with LS and NF, respectively.

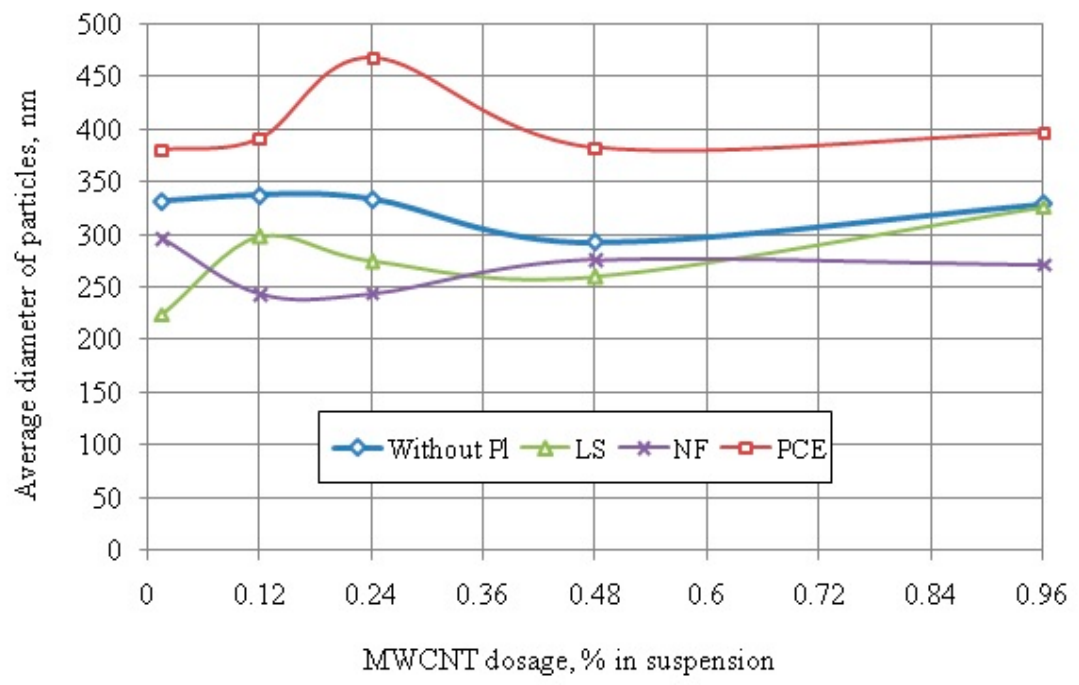

Figure 5. Average diameter of particles for MWCNT/CMC suspension with different Pl and MWCNT dosage [28]. 
Opposite to the effect of LS and NF, the increase in the average diameter up to $470 \mathrm{~nm}$ was observed for the MWCNT/CMC suspension with PCE. The different $\mathrm{pH}$ values of $\mathrm{Pl}$ can explain the differences in average particle size. PCE has a lower $\mathrm{pH}$ level in comparison with LS and NF (see Table 1) that causes additional agglomeration processes in the MWCNT/CMC suspension. Moreover, the carboxyl groups of the PCE plasticiser can be involved in the formation of intramolecular and intermolecular hydrogen bonds, with the carboxyl groups of the CMC located on the MWCNT surface, which result in the aggregation processes. LS and NF do not cause the aggregation of particles due to the absence of carboxyl groups in their molecular structure and other $\mathrm{pH}$ values. Therefore, LS and NF did not cause a significant increase in average particles size.

To evaluate the homogeneity of the MWCNT/CMC suspension, the polydispersity index (PDI) was calculated by particle size analyser software. PDI was evaluated for the MWCNT/CMC suspension with and without Pl. The PDI values are presented in Figure 6. Based on the results shown in Figure 6, it can be concluded that PDI reached the minimum values for all MWCNT/CMC suspensions, but in different MWCNT dosages and with different Pl.

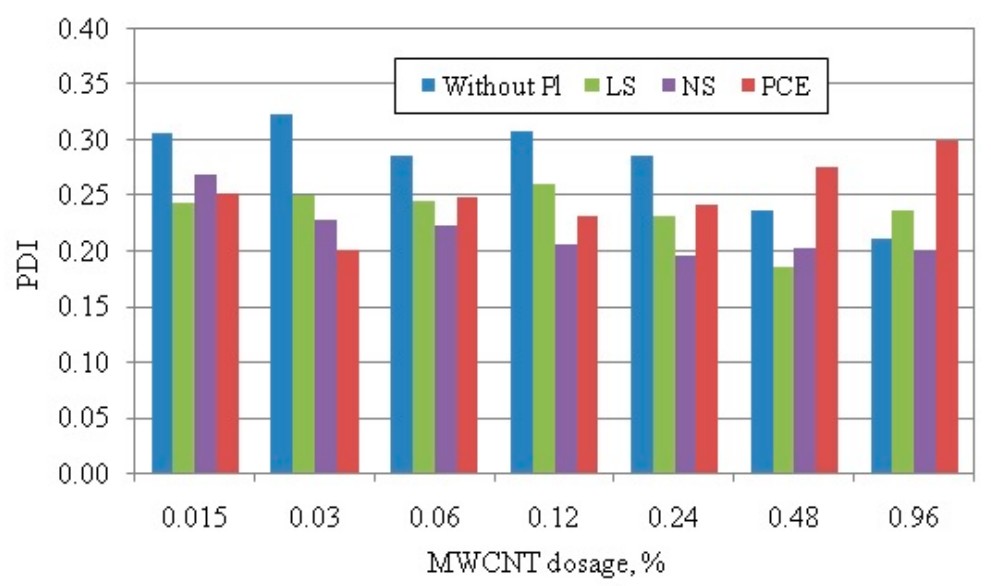

Figure 6. Polydispersity index (PDI) of MWCNT/CMC suspension with and without Pl.

In addition to the particle size analysis, the MWCNT/CMC suspension was characterised by the zeta potential measurements to evaluate the stability of the complex MWCNT/CMC suspension prepared in combination with $\mathrm{Pl}$ and their plasticising efficiency in cement-based materials (Figure 7).

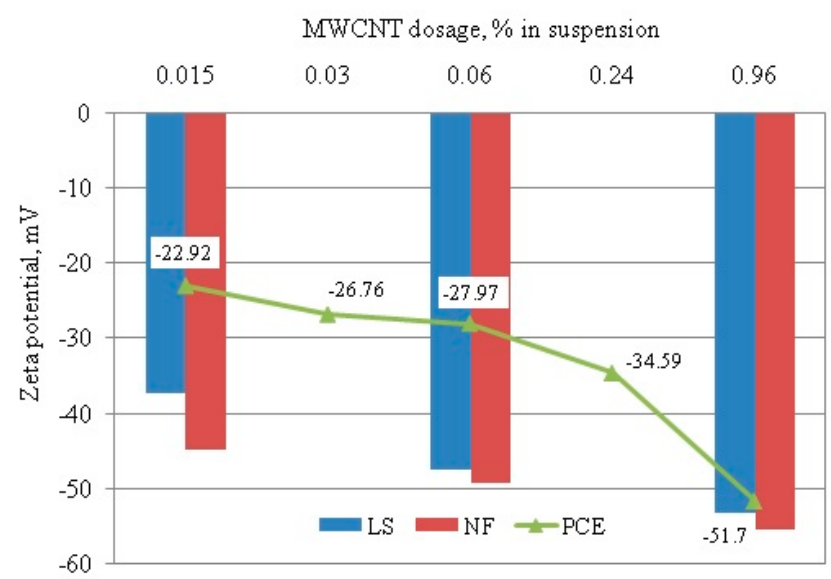

Figure 7. Zeta potential of MWCNT/CMC suspensions with different Pl and MWCNT dosages.

The LS, NF, and PCE show the different extents of the changes in zeta potential. The increase in zeta potential by $30 \%, 19 \%$, and $56 \%$ for LS, NF, and PCE plasticisers, respectively, was established with 
higher MWCNT dosage. The higher extent of the zeta potential changes was observed for PCE. The observed changes in the zeta potential can be associated with the differences in $\mathrm{pH}$ values of applied $\mathrm{Pl}$.

The observed properties of MWCNT/CMC suspension in the presence of different Pl determine their further impact on the rheological parameters of nanomodified cement-based materials.

\subsection{MWCNT Influence on the Plasticising Efficiency}

Figure 8 shows the changes in yield stress of cement paste modified by MWCNT in the dosage from 0 to $0.24 \%$ bwoc without Pl. The diagram indicates that yield stress increased with an increase in MWCNT dosage. The maximum increase in yield stress by $17 \%$ was observed for the cement paste with $0.24 \%$ bwoc of MWCNT in comparison with the cement paste without admixtures. The addition of MWCNT in the dosage from 0 to $0.24 \%$ bwoc to the cement paste increased the plastic viscosity. The maximum increase in the plastic viscosity by $6 \%$ was identified for the cement paste with $0.06 \%$ bwoc of MWCNT in comparison with the sample without admixture (Figure 8).

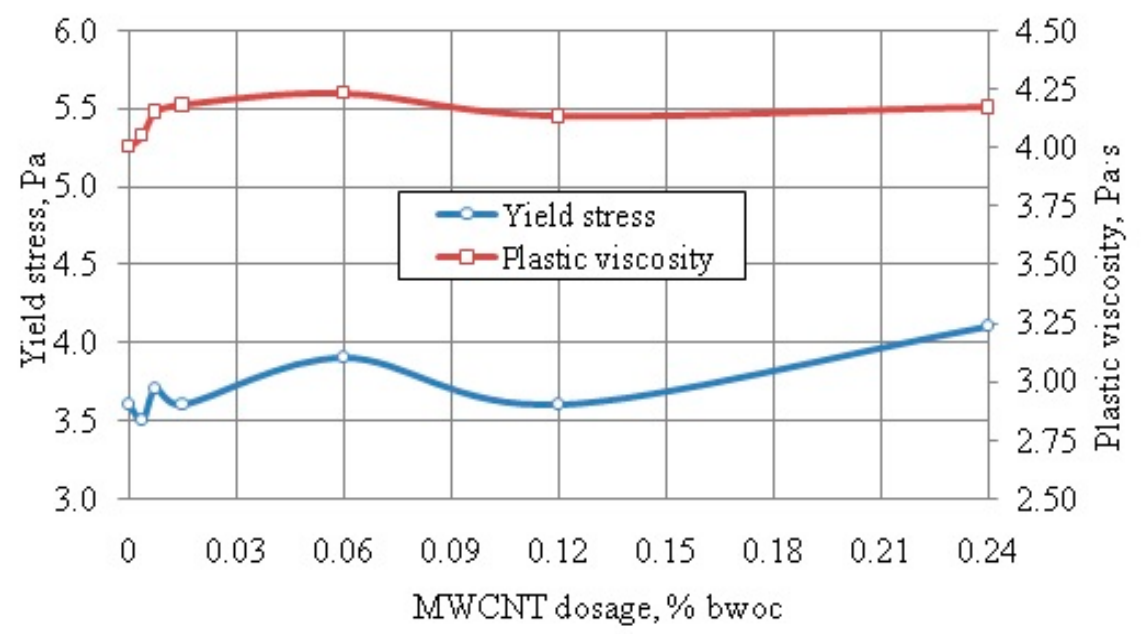

Figure 8. Rheological parameters of nanomodified cement paste without Pl.

The rheological parameters of the cement paste modified separately by CMC in the dosage of $0.29 \%$ bwoc were determined due to the presence of CMC in the MWCNT/CMC suspension as a dispersing agent. The yield stress and plastic viscosity were of $3.2 \mathrm{~Pa}$ and $2.65 \mathrm{~Pa} \cdot \mathrm{s} 5 \mathrm{~min}$ after cement paste mixing. These parameters are less than ones for the cement paste modified by the suspension with MWCNT dosage of $0.24 \%$ bwoc and equal to $4.1 \mathrm{~Pa}$ and $4.17 \mathrm{~Pa} \cdot \mathrm{s}$, respectively. It demonstrates that MWCNT leads to the additional increase in rheological parameters of the cement paste.

Modification of the cement paste by the MWCNT/CMC suspension and LS led to the increase in yield stress (Figure 9). The maximum increase in yield stress by $11 \%$ was reached for cement paste with $0.24 \%$ bwoc of MWCNT in comparison with cement paste only with LS. The plastic viscosity of the cement pastes with the MWCNT suspension and LS decreased up to the MWCNT dosage of $0.12 \%$ bwoc and started to increase over this dosage. The maximum increase in plastic viscosity by $9 \%$ for cement pastes with MWCNT of $0.24 \%$ bwoc and LS was identified, as is seen in Figure 9. 


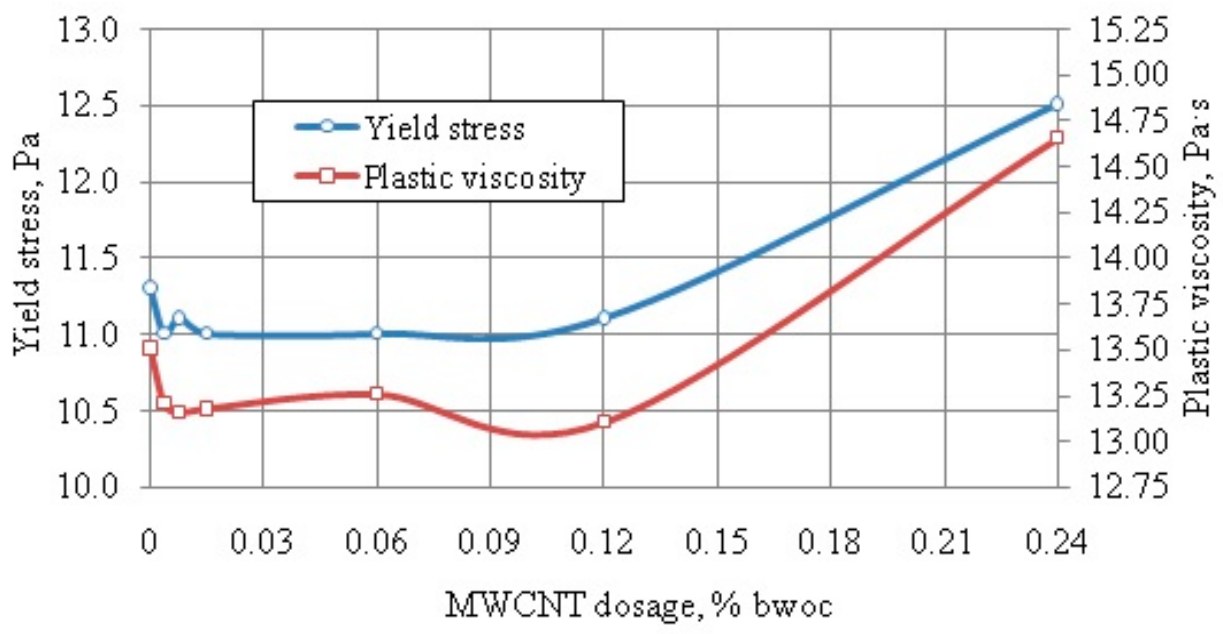

Figure 9. Rheological parameters of nanomodified cement paste with lignosulphonate (LS).

The yield stress of nanomodified cement paste in combination with NF decreased by $11 \%$ with a variation of MWCNT dosage from 0 to $0.24 \%$ bwoc. The modification of cement paste by $0.24 \%$ bwoc of MWCNT resulted in the increase in yield stress up to the value of yield stress for the cement paste only with NF. The plastic viscosity of the cement paste with the MWCNT suspension and NF decreased up to $13 \%$ in the range of MWCNT dosage from 0 to $0.12 \%$ bwoc. The increase inMWCNT dosage from $0.12 \%$ to $0.24 \%$ bwoc resulted in the change of plastic viscosity up to the value of plastic viscosity for the reference cement paste with NF (Figure 10).

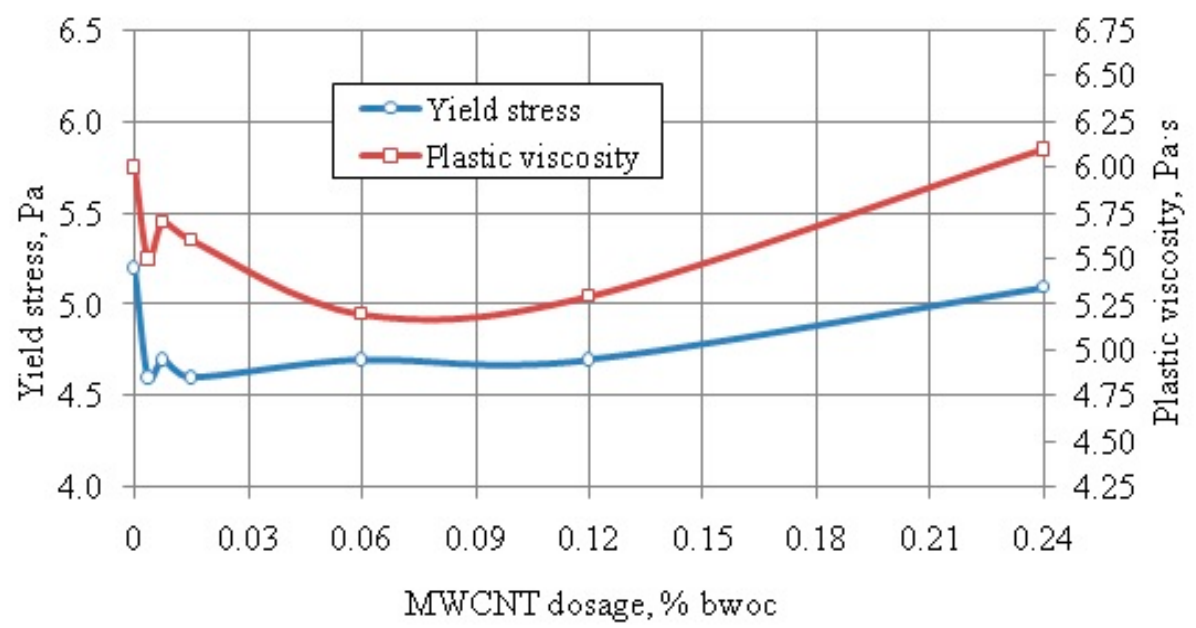

Figure 10. Rheological parameters of nanomodified cement paste with naphthalene formaldehyde condensate (NF).

Figure 11 represents the changes in yield stress of nanomodified cement paste with PCE. The yield stress was not changed up to the MWCNT dosage of $0.06 \%$ bwoc and increased above this dosage. The maximum increase in yield stress value by $265 \%$ was obtained in the MWCNT dosage of $0.12 \%$ with respect to the reference cement paste modified by PCE without MWCNT. 


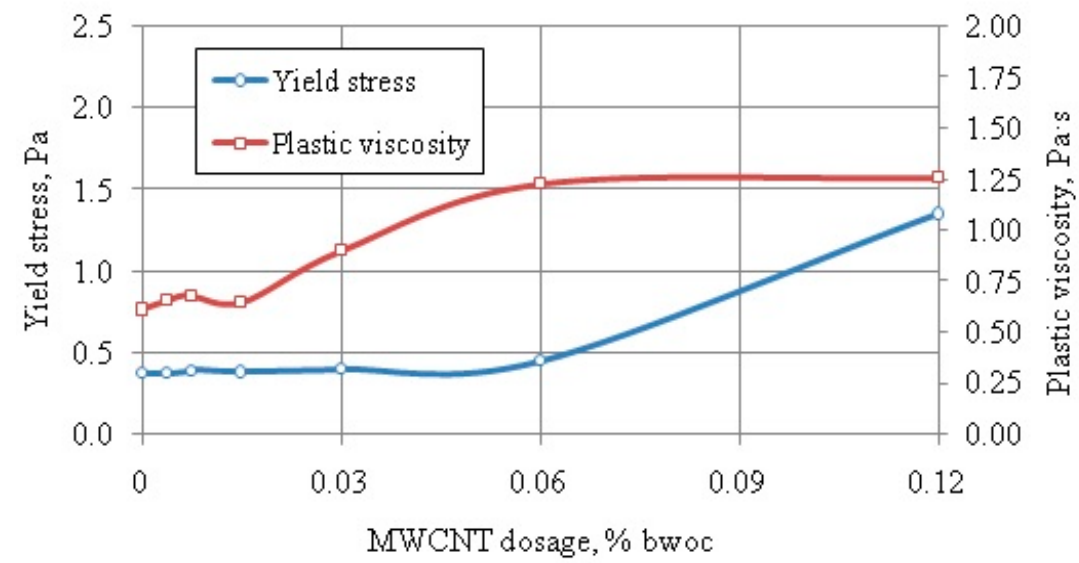

Figure 11. Rheological parameters of nanomodified cement paste with polycarboxylate ether (PCE).

The proportional increase in the plastic viscosity of the cement paste modified by the MWCNT/CMC suspension and PCE was observed from the MWCNT dosage of $0.015 \%$ bwoc up to $0.06 \%$ bwoc. Figure 11 shows that the more remarkable increase by $107 \%$ was established for the cement paste with $0.12 \%$ bwoc of MWCNT in the presence of PCE.

\subsection{MWCNT Influence on Flow Behaviour of Cement Paste}

In addition to the yield stress and plastic viscosity, the shear thinning/thickening (flow behaviour) indexes of nanomodified cement pastes with and without Pl were derived by means of the experimental curves approximation.

The changes in the shear thinning/thickening indexes depending on MWCNT dosage and type of $\mathrm{Pl}$ in 5 and $120 \mathrm{~min}$ after cement paste mixing are shown in Figure 12a,b, respectively. The cement paste without Pl and with LS and NF is characterised by the shear thinning flow behaviour $(n<1)$. Regarding the complex modification of cement paste by MWCNT with LS and NF, the shear thinning index slightly decreased from 0.70 to 0.64 and from 0.83 to 0.72 , respectively, with the introduction of MWCNT up to $0.06 \%$ bwoc. The addition of MWCNT caused a small decrease in thixotropy of cement pastes. Opposite to the effect of LS and NF, the nanomodified cement pastes with PCE represented the occurrence of shear thickening flow behaviour $(n>1)$. With an increase in MWCNT dosage over $0.03 \%$ bwoc, the shear thickening index of cement paste with PCE and MWCNT slightly decreased from 1.20 to 1.17. In other words, the addition of MWCNT to the cement pastes plasticised by PCE decreased the dilatancy. The observation of shear thickening behaviour of PCE correlates with the results of the research works presented in $[40,52]$. Mainly, the shear thinning/thickening indexes are determined by the type of $\mathrm{Pl}$ and do not depend significantly on MWCNT dosage. The flow behaviour indexes were not changed remarkably 120 min after cement paste mixing (see Figure 12b). 

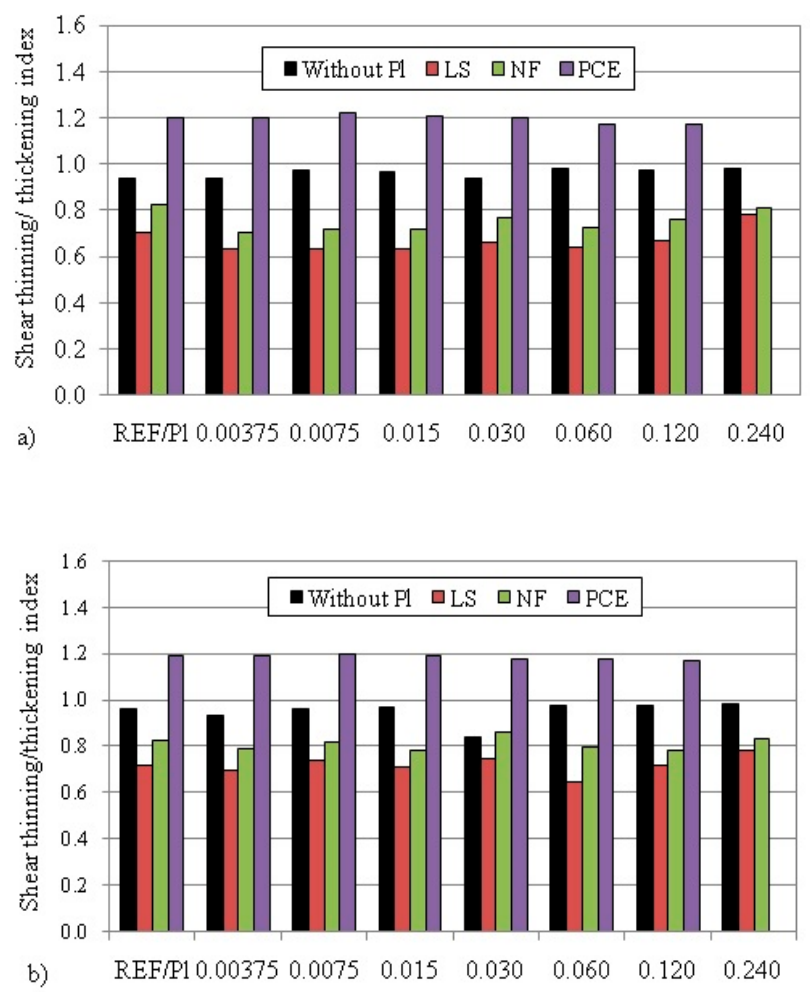

Figure 12. Shear thinning/thickening index of the nanomodified cement paste without and with Pl 5 min (a) and $120 \mathrm{~min}(\mathbf{b})$ after cement paste mixing.

\subsection{MWCNT Influence on the Duration of Plasticising Effect}

The rheological properties of cement paste modified by the MWCNT/CMC suspension with and without $\mathrm{Pl}$ were tested 5, 60, and $120 \mathrm{~min}$ after cement paste mixing to evaluate the plasticising efficiency of the admixtures in time. Modification of the cement paste by the MWCNT/CMC suspension with and without Pl did not have a significant impact on the yield stress in time after cement paste mixing.

Figure 13 demonstrates that yield stress of the cement paste modified by the MWCNT/CMC suspension without Pl linearly increases for $120 \mathrm{~min}$ after cement paste mixing. The character of dependence between yield stress and time after cement paste mixing remained similar for all cement paste, with MWCNT dosages varying from 0 to $0.24 \%$. The changes in yield stress $120 \mathrm{~min}$ after cement paste mixing did not exceed $10 \%$ for all tested cement pastes in comparison with samples after 5 min of mixing.

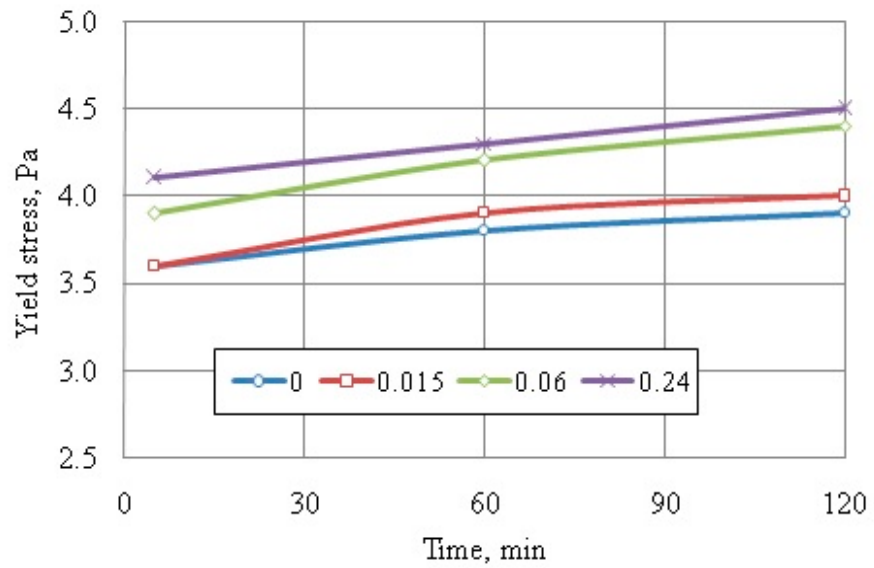

Figure 13. Yield stress of nanomodified cement paste without Pl in 5, 60, and $120 \mathrm{~min}$ after cement paste mixing. 
The yield stress of cement pastes modified by the MWCNT/CMC suspension in combination with LS did not remarkably increase from 5 to $120 \mathrm{~min}$ after cement paste mixing. The increase in yield stress of cement paste $120 \mathrm{~min}$ after cement paste mixing did not exceed $4 \%$ in comparison with yield stress $5 \mathrm{~min}$ after cement mixing. The MWCNT dosage did not have an impact on the dependence between yield stress and time after cement paste mixing.

The combined usage of NF and the MWCNT/CMC suspension led to the proportional increase in yield stress during the $120 \mathrm{~min}$ after cement paste mixing. The maximum increase in yield stress 120 min after cement paste mixing was of $20 \%$.

The yield stress of the cement paste modified by the MWCNT/CMC suspension with PCE (see Figure 14) was not changed during the $120 \mathrm{~min}$ after cement paste mixing up to a MWCNT dosage of $0.06 \%$ bwoc. The increase in MWCNT dosage up to $0.12 \%$ bwoc resulted in the decrease in yield stress from 60 to $120 \mathrm{~min}$ after cement paste mixing by $11 \%$ in comparison with cement paste $5 \mathrm{~min}$ after mixing.

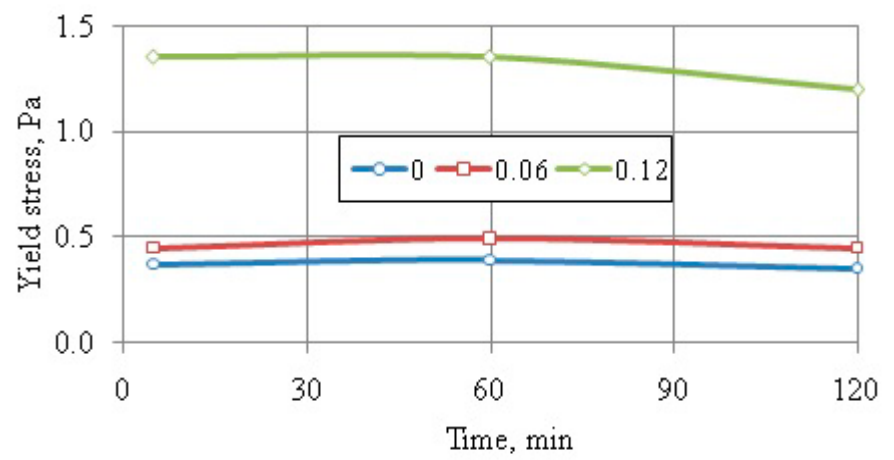

Figure 14. Yield stress of nanomodified cement paste with PCE 5, 60, and 120 min after cement paste mixing.

The character of dependence between plastic viscosity and time after cement paste mixing had differences in the presence of $\mathrm{Pl}$ of various origins. The addition of MWCNT to cement paste did not have any impact on the dependence between plastic viscosity and time after cement paste mixing.

Figure 15 represents the dependence between plastic viscosity and time after cement paste mixing in the case of modification of the cement paste by MWCNT in the dosage from 0 to $0.24 \%$ bwoc without $\mathrm{Pl}$. The plastic viscosity linearly increased from 5 to $120 \mathrm{~min}$ after cement paste mixing. The increase in plastic viscosity during the time by $6 \%$ and $8 \%$ was identified for cement pastes without admixture and MWCNT dosage of $0.12 \%$ bwoc, respectively. The same character of curves was observed for cement pastes with other MWCNT dosages.

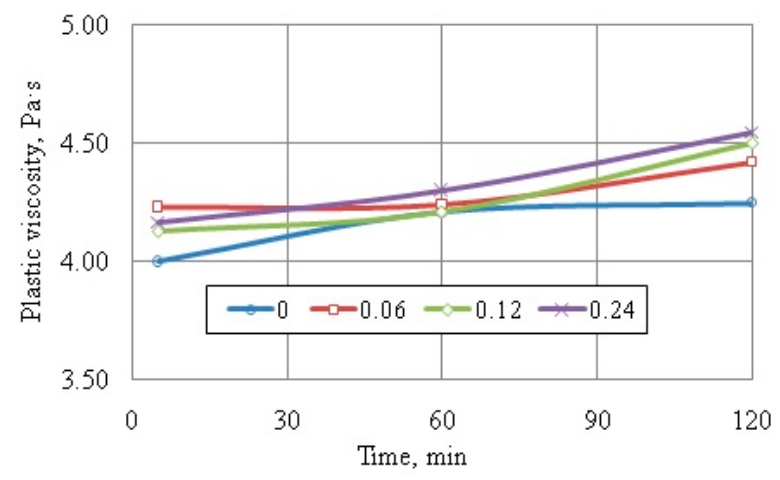

Figure 15. Plastic viscosity of nanomodified cement paste without Pl 5, 60, and 120 min after cement paste mixing. 
The cement pastes with the MWCNT/CMC suspension and LS were characterised by a remarkable increase in plastic viscosity in the first $60 \mathrm{~min}$ after cement paste mixing. The plastic viscosity increased by $21 \%$ for the reference cement paste with LS and by $15 \%$ for the cement paste modified by $0.24 \%$ bwoc of MWCNT in 120 min after cement paste mixing in comparison with values of plastic viscosity after $5 \mathrm{~min}$. The character of curves for the cement paste with a MWCNT dosage less than $0.24 \%$ bwoc was the same as for the reference sample only with LS.

The plastic viscosity of the nanomodified cement pastes with NF linearly increased from 5 to 120 min after cement paste mixing. The plastic viscosity of the reference cement paste with NF and without MWCNT/CMC suspension enhanced by $8 \%$ during the 120 min after cement paste mixing. The maximum increase in plastic viscosity by $23 \%$ during the 120 min after cement paste mixing was established for the cement paste modified by $0.06 \%$ bwoc of MWCNT. The other MWCNT dosages led to an increase in plastic viscosity of cement pastes during the time after cement paste mixing of no more than $9 \%$, in comparison with values of the plastic viscosity $5 \mathrm{~min}$ after cement paste mixing.

The modification of cement pastes by the MWCNT/CMC suspension and PCE decrease the plastic viscosity of cement paste during the time after cement paste mixing (Figure 16). The plastic viscosity of the cement pastes with PCE and MWCNT in the dosage of $0.03 \%, 0.06 \%$, and $0.12 \%$ was not changed during the first $60 \mathrm{~min}$ after cement paste mixing and decreased by $8 \%$ during the next $60 \mathrm{~min}$.

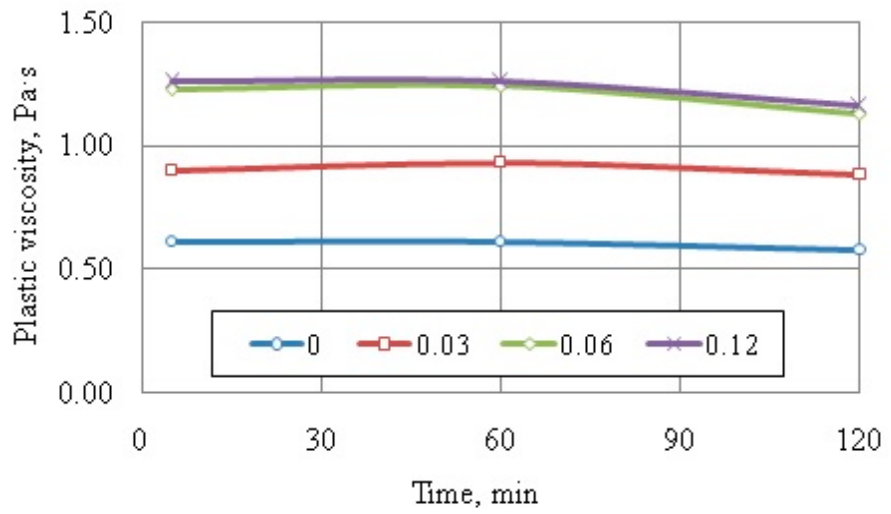

Figure 16. Plastic viscosity of nanomodified cement paste with PCE 5, 60, and 120 min after cement paste mixing.

\subsection{MWCNT Influence on Water Bleeding of Cement Paste}

The bleeding of cement pastes modified by MWCNT/CMC suspension without and with different types of $\mathrm{Pl}$ was estimated. The increase in MWCNT dosage in cement pastes with all Pl contributed to the reduction in the volume coefficient of water bleeding. Water bleeding of nanomodified cement pastes can be described by the exponential dependence between the coefficient of water bleeding $(\mathrm{K})$ and MWCNT dosage (Dnt) (see Figure 17). The exponential dependence with correlation coefficients $0.99,0.92$, and 0.94 was identified for nanomodified cement paste with LS, NF, and PCE, respectively, and 0.81 for cement paste without Pl. 


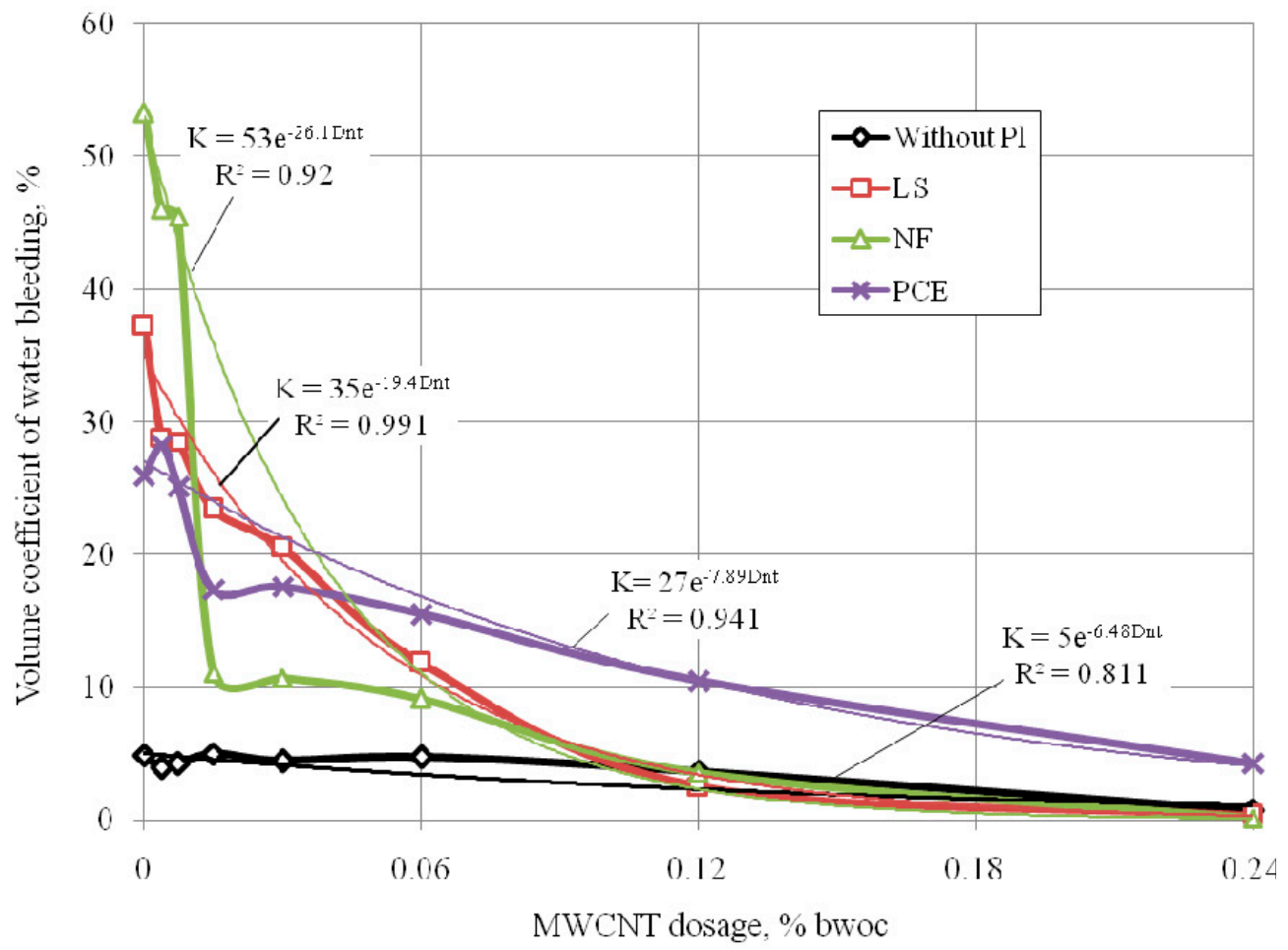

Figure 17. Water bleeding of nanomodified cement pastes with and without Pl.

Water bleeding was not changed up to the MWCNT dosage of $0.12 \%$ bwoc and decreased in the dosage of $0.24 \%$ bwoc for cement paste without Pl. The decrease in the volume coefficient of water bleeding was of $85 \%$ in comparison with the reference sample without MWCNT modification.

The addition of $\mathrm{Pl}$ led to more liquid consistency of the cement systems and more significant water bleeding in comparison with samples without Pl. The volume coefficient of water bleeding in cement pastes with LS, NF, and PCE remarkably reduced up to the MWCNT dosage of $0.015 \%$ bwoc and gradually reduced over this dosage. The reduction in the volume coefficient of water bleeding reached the values of $99 \%, 100 \%$, and $83 \%$ for LS, NF, and PCE, respectively, with an increase in MWCNT dosage up to $0.24 \%$ bwoc. The volume coefficient of the water bleeding reached values closer to 0 with the MWCNT dosage of $0.24 \%$ bwoc in cement systems without Pl and with LS and NF.

Taking into account the presence of CMC in the MWCNT/CMC suspension, a bleeding test was performed for the cement systems modified by CMC separately and CMC with PCE. Figure 18 shows the water bleeding test for the reference sample without any admixtures, for cement systems with CMC, PCE, CMC with PCE, and the MWCNT/CMC suspension (with PCE). The MWCNT dosage was of $0.06 \%$ bwoc in this experiment. The CMC dosage in accordance with MWCNT dosage was of $0.07 \%$ bwoc. 


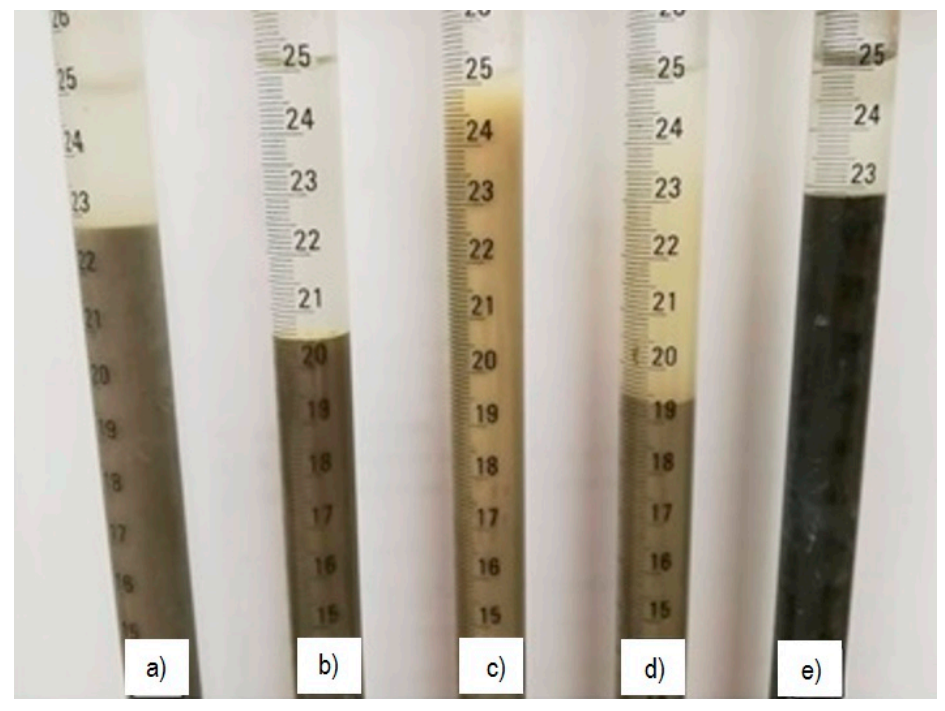

Figure 18. Bleeding test for cement pastes without admixtures (a); with carboxymethyl cellulose (CMC) (b); PCE (c); CMC and PCE (d); and MWCNT/CMC suspension and PCE (e).

The bleeding test revealed that the addition of PCE leads to bleeding not only of water but also of a liquid phase with polymer (Figure 18c). The complex modification by CMC and PCE results in changes in the bleeding liquid phase. Figure 18d demonstrates the light-yellow colour of the liquid phase in comparison with the sample in Figure 18c that can be linked with the formation of chemical bonding between functional groups of CMC and PCE. The cement systems modified by the MWCNT/CMC suspension and PCE present the absence of the liquid phase like it is for samples in Figure $18 \mathrm{c}, \mathrm{d}$ and the value of bleeding water on the level of the reference sample (see Figure 18a). According to Figure 18, it can be concluded that the effect of CMC (as a dispersing agent of the MWCNT/CMC suspension) in the bleeding test of the cement paste can be omitted due to the absence of a significant influence on the water bleeding of the cement paste.

\section{Discussion}

\subsection{Rheological Properties of Cement Paste}

\subsubsection{Steric Effect}

The combined action mechanism of MWCNT and Pl in cement systems requires a deep investigation. MWCNT possesses high inner and outer surface area, porous structure, and high aspect ratio $[16,17,53]$, which can change not only the resulting properties of nanomodified cement-based mixtures, but also can firstly affect the action mechanism of Pl. It is well-known that the electrostatic and steric effects determine the ability of $\mathrm{Pl}$ to prevent flocculation and provide well dispergation of cement particles in the concrete mixture. Moreover, one of the main factors, which provides the plasticising effect, is the decrease in surface tension on the surface of cement particles in mixing water with Pl [54-56].

The electrostatic effect is more typical for $\mathrm{Pl}$ of the previous generation, such as LS and NF. The placement of negative charge of $\mathrm{Pl}$ on the cement particle leads to changes in zeta potential in the cement system and the appearance of electrostatic repulsive forces between cement particles. The neutralisation of the attractive forces between cement particles through the electrostatic repulsive forces facilitates the dispergation of cement particles and the increase in fluidity of cement systems [54]. The working mechanism of Pl of the last generation, such as PCE, is based on steric hindrance and electrostatic effects. A number of researchers $[55,56]$ highlighted the dominant character of the steric 
effect, which depends on the extension of side chains in aqueous solution. The steric effect enables the preservation of the plasticising effect for a long period of time.

Figure 19a,b present the scheme of interaction on the cement grains surface with and without Pl. The scheme in Figure 19c proposed the possible interaction, which can be on the cement grains surface in the presence of MWCNT and Pl.

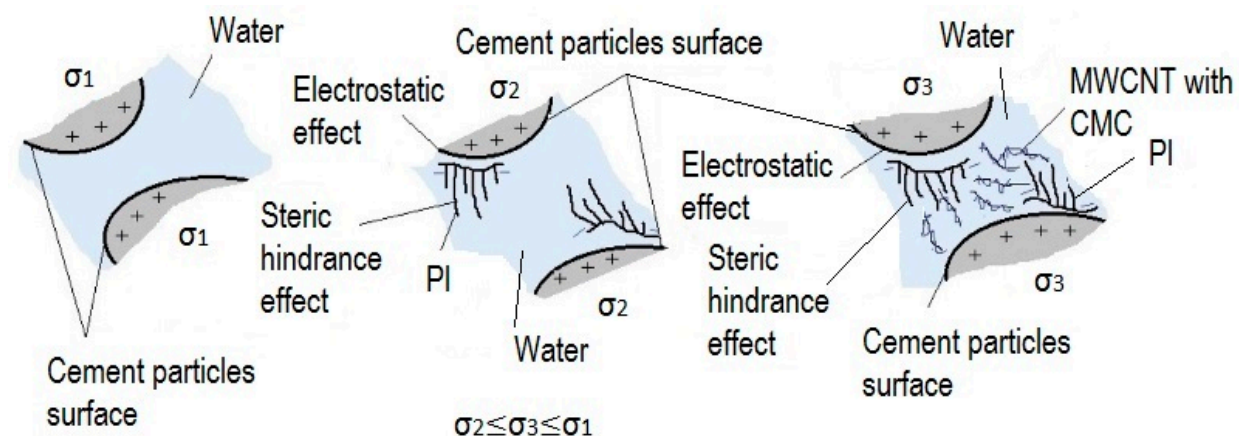

a)

b)

c)

Figure 19. Interaction on the cement grains surface without admixtures (a); with $\mathrm{Pl}(\mathbf{b})$; with $\mathrm{Pl}$ and MWCNT (c), where $\sigma$ is the surface tension on the surface of cement particles in mixing water.

In the current and previous research works [27-29], the rheological properties were evaluated for investigation of the plasticising effect and understanding of the working mechanism of MWCNT in the cement systems. The addition of MWCNT in the complex with Pl affects the steric effect in the cement paste due to the placement of fibre-shaped MWCNT with high length in the volume between cement particles (Figure 19c). The impact of MWCNT on the steric effect in the cement system can be stronger in the case of better homogenisation of nanoparticles in the aqueous suspension. Therefore, the effective method of homogenisation of MWCNT suspension with Pl is necessary for the improvement of the steric effect and plasticising efficiency of complex admixture in the cement-based materials. A number of researchers highlighted the importance of MWCNT suspension homogenisation and its correlation with properties of cement-based materials in a fresh and hardened state $[15,17]$. The impact of MWCNT on the steric effect in the cement paste can also be a reason for a prolongation of the plasticising effect in time. The prolongation of the plasticising effect was observed in the present research for nanomodified cement paste with PCE. MWCNT dosages above $0.03 \%$ bwoc caused the decrease in yield stress and plastic viscosity during $120 \mathrm{~min}$ after cement paste mixing (Figures 14 and 16). Thus, the plasticising effect of the cement paste with PCE can be kept or enhanced for a longer time with modification by certain MWCNT dosages. The cement pastes modified by MWCNT/CMC suspension separately (Figures 13 and 15) or in combination with LS and NF (see Section 3.4) did not demonstrate the enhancement in the duration of the plasticising effect as for PCE. Such difference can be explained by the differences in action mechanism of these $\mathrm{Pl}$, which was described above.

\subsubsection{Surface Area and Particles Distribution Density Effect}

The decisive factor, which determines the properties of nanomodified cement systems, is a high surface area of nanoparticles $[10,25,57,58]$ and their extremely fine size. According to Reales et al. [25], the surface area of MWCNT is equal to $208.0 \mathrm{~m}^{2} / \mathrm{g}$, which is three orders more than for cement particles. In the present research, the principle of photon correlation spectroscopy underlies the particle size measurements. The average particle size for the MWCNT suspension with LS, NF, and PCE was established equal to 220, 240, and $470 \mathrm{~nm}$, respectively (Figure 5). The high surface area of MWCNT contributes to the remarkable adsorption and retention of water in the cement mixture $[10,58]$. The addition of the MWCNT suspension in definite dosages leads to the retention of water, which contributes to the increase in physically bounded water content in cement mixture. The retention of 
water causes a further increase in yield stress and plastic viscosity in comparison with cement mixture of the same W/C without the MWCNT suspension. The ability of MWCNT in definite dosages to reduce the free water content in cement systems decreases the plasticising efficiency of $\mathrm{Pl}$ and, as a consequence, the flowability of cement paste. The rheological tests of the present and previous research works $[25,27,59]$ revealed that MWCNT addition with the achievement of specific dosages increases the values of the yield stress and plastic viscosity of cement-based mixtures.

Afurther aspect, which determines the properties of nanomodified cement paste in a fresh state, is the distribution of solid particles in mixture. Particle size is one of the factors which define the rheological properties of cement systems $[60,61]$. Figure 20 demonstrates the results of particle size analysis for Portland cement without mineral additives and the MWCNT suspension. The average value of cement particles was about $14 \mu \mathrm{m}$, whereas an average diameter of nanoparticles was about $290 \mathrm{~nm}(0.290 \mu \mathrm{m})$ (red curve in Figure 20). It can be concluded that cement particles have a size 50 times more than one for the aggregates of MWCNT suspension. Such difference in size has one of the key roles in changes of the density of distribution of solid particles in cement paste and, as consequence, affects the rheological parameters and flow behaviour of cement paste.

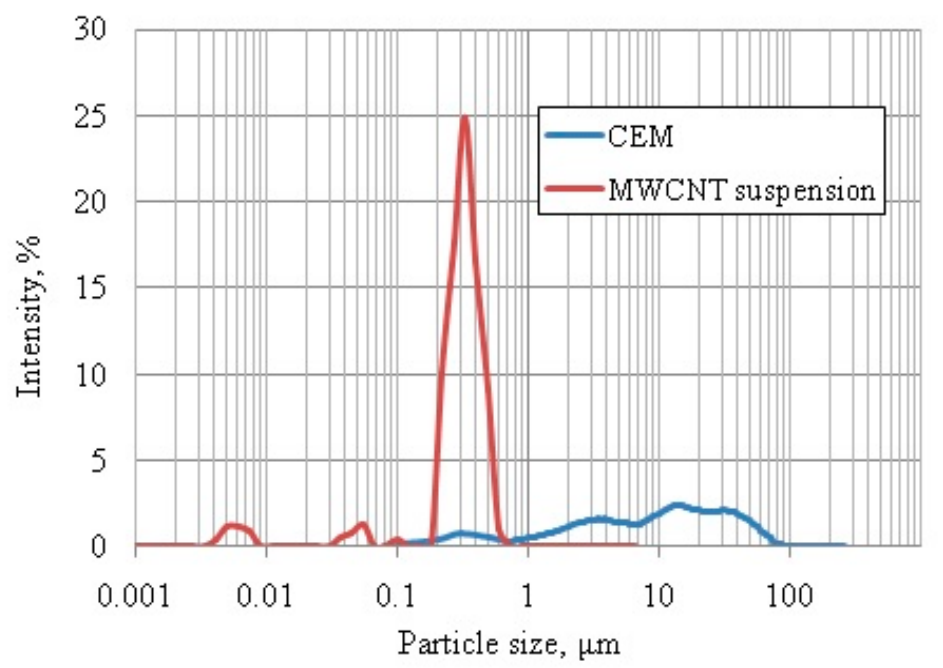

Figure 20. The particle size distribution for MWCNT suspension and Portland cement.

According to Figures 8-10, the yield stress and plastic viscosity of nanomodified cement paste were not changed remarkably. This phenomenon can be linked with the complex effect of the increase in surface area together with the increase in the distribution density of solid particles in the cement system volume with the addition of MWCNT. The first effect increases the yield stress and plastic viscosity of the cement paste, whereas the second one decreases them. With the achievement of definite MWCNT dosages, the effect of surface area becomes dominant in comparison with the effect of distribution density and causes an increase in yield stress and plastic viscosity of cement-based mixtures. The increase in yield stress and plastic viscosity were noticed from the different MWCNT dosages in the presence of various types of $\mathrm{Pl}$, which can be linked with different chemical structure of polymers (Figures 9-11).

The complex effect of MWCNT/CMC suspension and Pl on the rheology of cement paste is linked with the absorption of $\mathrm{Pl}$ on the surface of cement grains and cement hydration products (see Figure 19b,c), which cause the formation of complex chemical compounds with ions of cement. The addition of MWCNT covered by CMC can affect the formation of these compounds as well (interactions of carboxyl groups of $\mathrm{CMC}$ and functional groups of $\mathrm{Pl}$, see Section 4.1.3) and cause the changes in $\mathrm{pH}$ values, and, as a consequence, affect the zeta potential on the cement grains and surfaces of cement hydration products surfaces and MWCNT. Afterwards, the changes in zeta potential affect the plasticising effect in the cement system. 


\subsubsection{Chemical Interaction Effect}

The type of dispersing agent for homogenisation of MWCNT in the volume of the aqueous suspension affects rheological properties of the nanomodified cement pastes $[10,25,26,58]$. In the present research, CMC was used as a dispersing agent (CMC) for MWCNT homogenisation. The chemical bonds between dispersing agents, functional groups of $\mathrm{Pl}$, and ions of cement hydration products can form the complexes, which contribute to the shear thickening effect of cement mixtures. The MWCNT with molecules of CMC may chemically interact with cement hydration products.

The first explanation of the viscosity-enhancing effect in cement systems modified by MWCNT might be that $\mathrm{Ca}^{2+}$ ions are combined with several ethers (R-O-R), carboxylate (R-COO-), or carboxyl $(-\mathrm{COOH})$ groups in Pl. In the case of cement paste modification by $\mathrm{PCE}, \mathrm{Ca}^{2+}$ ions can also be combined with several groups in CMC or PCE molecules. In other words, the intramolecular interactions may take place between $\mathrm{Ca}^{2+}$ ions, PCE, and MWCNT with CMC molecules [61,62].

The second explanation might be that ether groups and hydroxyl groups polarise the water molecules and form hydrogen bonds. The formed hydrogen bonds can crosslink several polymer molecules together and provide the increase in yield stress and plastic viscosity of nanomodified cement systems with PCE. The proposed scheme of chemical interaction between $\mathrm{Ca}^{2+}$, molecules of CMC, and PCE is presented in Figure 21.

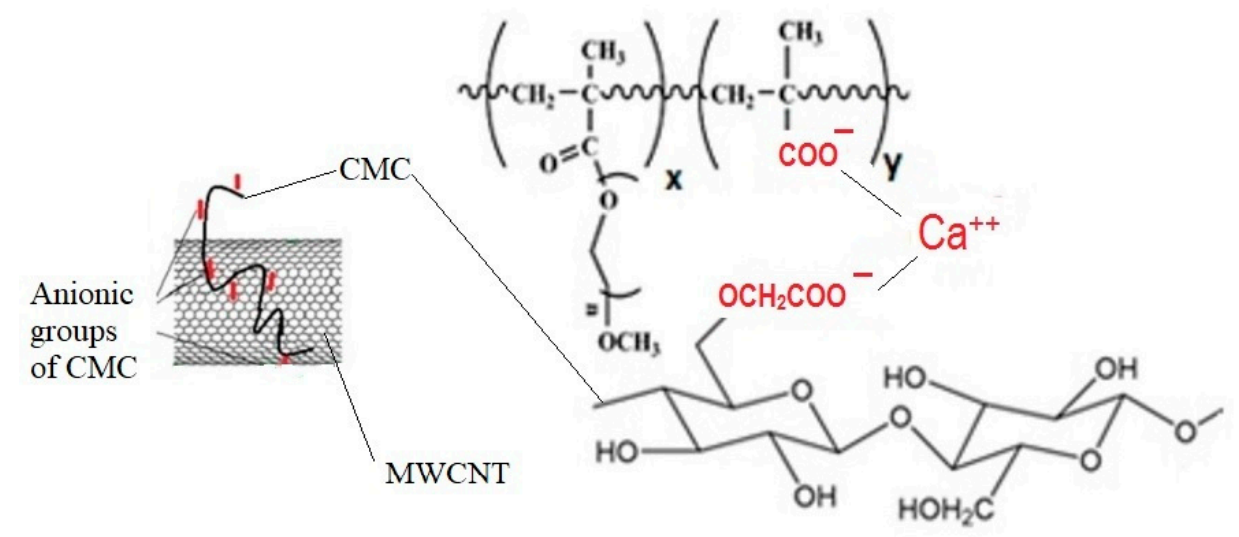

Figure 21. The scheme of chemical interaction between $\mathrm{CMC}, \mathrm{Ca}^{2+}$ ions of cement paste and PCE.

The nanomodified cement paste without Pl and with LS and NF did not demonstrate a significant increase in yield stress and plastic viscosity with the increase in MWCNT dosage. The observed phenomenon may be explained by the absence of carboxyl (-COOH) groups in LS and NF that are followed by the increase in zeta potential $[37,39]$. The absence of chemical interactions decreases the effect of MWCNT and leads to insignificant changes in the yield stress and plastic viscosity of cement pastes with these Pl.

\subsection{Water Bleeding of Cement Paste}

As was observed in the water bleeding test (Figure 17), the increase in MWCNT dosage up to $0.24 \%$ bwoc noticeably decreases the volume coefficient of water bleeding in cement pastes with all kinds of Pl. The dependence between water bleeding and MWCNT dosage is expressed by exponential dependence (see Figure 17), which can be used for prediction of water bleeding of plasticised cement pastes with MWCNT. The significant increase in surface area of the solid phase of cement paste with the introduction of small particles of MWCNT (Figure 20) causes the significant decrease in free water content and, as a consequence, a water bleeding of cement paste. The considerable decrease in the volume coefficient of water bleeding was observed up to a MWCNT dosage of $0.015 \%$ bwoc. The higher dosages of MWCNT constantly reduce the water bleeding of cement paste up to the value close to zero percent. The increase in MWCNT dosage from $0 \%$ bwoc up to $0.24 \%$ bwoc led to the decrease in 
volume coefficient of water bleeding by $99 \%, 100 \%$, and $83 \%$ for cement pastes modified by LS, NF, and PCE, respectively. The observed effect of MWCNT on the water bleeding of the cement pastes can be explained by the high surface area and porous structure of MWCNT, which can retain water, decrease the level of free water, and increase the physically bounded water content in cement paste $[10,58]$.

\section{Conclusions}

- The cement pastes without and with LS and NF plasticising admixtures possess shear thinning flow behaviour $(n<1)$, with PCE-the shear thickening flow behaviour $(n>1)$. MWCNT do not have a significant influence on the flow behaviour of cement paste; however, in the case of use of PCE, the shear thickening effect decreased from a MWCNT dosage of $0.03 \%$ bwoc. Mainly, the flow behaviour of the cement paste is determined by the type of applied plasticising admixture.

- The MWCNT suspension increases yield stress and plastic viscosity of cement pastes but to different extents depending on the type of plasticising admixture. More remarkable changes in rheological parameters were observed for nanomodified cement paste with PCE due to a combination of physical and chemical interactions in the nanomodified cement systems. The increases in yield stress and plastic viscosity of cement paste by $265 \%$ and $107 \%$, respectively, were established with an increase in MWCNT dosage up to $0.12 \%$ bwoc.

- The complex modification of cement paste by the MWCNT suspension with LS and NF changes the yield stress and plastic viscosity no more than $10-20 \%$.

- The addition of MWCNT to the cement pastes enables the maintenance of the plasticising effect of admixtures for more than $2 \mathrm{~h}$. The yield stress and plastic viscosity of nanomodified cement paste without plasticising admixture and with LS and NF slightly increased during the 120 min after cement paste mixing (up to $23 \%$ ). The addition of MWCNT in the dosage over $0.03 \%$ bwoc to the cement pastes with PCE slightly decreased the yield stress and plastic viscosity during the 120 min after cement paste mixing (up to $11 \%$ ) due to the improvement of the steric effect.

- The shear thinning/thickening indexes of MWCNT-modified cement pastes remained constant for all types of plasticising admixture during the $120 \mathrm{~min}$ after cement paste mixing.

- Modification of cement paste by MWCNT with its high surface area resulted in the reduction in the volume coefficient of water bleeding by $85 \%, 99 \%, 100 \%$, and $83 \%$, respectively, for the MWCNT suspension without plasticising admixture and with LS, NF, and PCE with an increase in MWCNT dosage up to $0.24 \%$ bwoc.

- The decrease in water bleeding of plasticised cement pastes with an increase in MWCNT dosage can be expressed by exponential dependence.

- The current research proposed the action mechanisms of MWCNT in plasticised cement systems, which consist of changes in the ordinary steric effect of plasticisers, the effect of the high surface area of MWCNT, particles distribution density, and chemical interaction.

Author Contributions: Conceptualisation and methodology, G.S. and E.K.; investigation, E.K., G.S., J.B., and I.B.; data curation, E.K.; writing—original draft preparation, E.K., G.S.; writing—review and editing, E.K., G.S., J.B., and I.B.; visualisation, E.K.; supervision, G.S. All authors have read and agreed to the published version of the manuscript.

Funding: This research was funded by the Research Council of Lithuania, grant number 320165329-1.

Acknowledgments: We are grateful to the Research Council of Lithuania for covering the PhD research of E. Karpova.

Conflicts of Interest: The authors declare no conflict of interest.

\section{References}

1. Kostrzanowska-Siedlarz, A.; Golaszewski, J. Rheological properties of high performance self-compacting concrete: Effects of composition and time. Constr. Build. Mater. 2016, 115, 705-715. [CrossRef] 
2. Kim, J.S.; Kwon, S.H.; Jang, K.P.; Choi, M.S. Concrete pumping prediction considering different measurement of the rheological properties. Constr. Build. Mater. 2018, 171, 493-503. [CrossRef]

3. Feys, D.; Khayat, K.H.; Khatib, R. How do concrete rheology, tribology, flow rate and pipe radius influence pumping pressure? Cem. Concr. Compos. 2016, 66, 38-46. [CrossRef]

4. Wu, Q.; An, X. Development of a mix design method for SCC based on the rheological characteristics of paste. Constr. Build. Mater. 2014, 53, 642-651. [CrossRef]

5. Esmaeilkhanian, B.; Khayat, K.H.; Yahia, A.; Feys, D. Effects of mix design parameters and rheological properties on dynamic stability of self-consolidating concrete. Cem. Concr. Compos. 2014, 54, 21-28. [CrossRef]

6. Wallevik, J.E.; Wallevik, O.H. Concrete mixing truck as a rheometer. Cem. Concr. Res. 2020, 127, 105930. [CrossRef]

7. Lomboy, G.R.; Wang, X.; Wang, K. Rheological behavior and formwork pressure of SCC, SFSCC, and NC mixtures. Cem. Concr. Compos. 2014, 54, 110-116. [CrossRef]

8. Mueller, F.V.; Wallevik, O.H.; Khayat, K.H. Linking solid particle packing of eco-SCC to material performance. Cem. Concr. Compos. 2014, 54, 117-125. [CrossRef]

9. Banfill, P.F.G. The rheology of fresh cement and concrete-A review. In Proceedings of the 11th International Congress on the Chemistry of Cement, Durban, South Africa, 11-16 May 2003; Volume 1, pp. 50-62.

10. Jiang, S.; Shan, B.; Ouyang, J.; Zhang, W.; Yu, X.; Li, P.; Han, B. Rheological properties of cementitious composites with nano/fiber fillers. Constr. Build. Mater. 2018, 158, 786-800. [CrossRef]

11. Shang, Y.; Zhang, D.; Yang, C.; Liu, Y.; Liu, Y. Effect of graphene oxide on the rheological properties of cement pastes. Constr. Build. Mater. 2015, 96, 20-28. [CrossRef]

12. Kawashima, S.; Kim, J.H.; Corr, D.J.; Shah, S.P. Study of the mechanisms underlying the fresh-state response of cementitious materials modified with nanoclays. Constr. Build. Mater. 2012, 36, 749-757. [CrossRef]

13. Li, H.; Ding, S.; Zhang, L.; Ouyang, J.; Han, B. Effect of particle size, crystal phase and surface treatment of nano- $\mathrm{TiO}_{2}$ on the rheological parameters of cement paste. Constr. Build. Mater. 2020, 239, 117897. [CrossRef]

14. Senff, L.; Hotza, D.; Lucas, S.; Ferreira, V.M.; Labrincha, J.A. Effect of nano-SiO 2 and nano-TiO 2 addition on the rheological behavior and the hardened properties of cement mortars. Mater. Sci. Engin. A 2012, 532, 354-361. [CrossRef]

15. Reales, O.A.M.; Filho, R.D.T. A review on the chemical, mechanical and microstructural characterization of carbon nanotubes-cement based composites. Constr. Build. Mater. 2017, 154, 697-710. [CrossRef]

16. Shi, T.; Li, Z.; Gong, H.; Gu, C. Research progress on CNTs/CNFs-modified cement-based composites-A review. Constr. Build. Mater. 2019, 202, 290-307. [CrossRef]

17. Rashad, A.M. Effect of carbon nanotubes (CNTs) on the properties of traditional cementitious materials. Constr. Build. Mater. 2017, 153, 81-101. [CrossRef]

18. Cui, X.; Han, B.; Zheng, Q.; Yu, X.; Dong, S.; Zhang, L.; Ou, J. Mechanical properties and reinforcing mechanisms of cementitious composites with different types of multiwalled carbon nanotubes. Compos. Part A 2017, 103, 131-147. [CrossRef]

19. Parveen, S.; Rana, S.; Fangueiro, R.; Paiva, M.C. Microstructure and mechanical properties of carbon nanotube reinforced cementitious composites developed using a novel dispersion technique. Cem. Concr. Res. 2015, 73, 215-227. [CrossRef]

20. Collins, F.; Lambert, J.; Duan, W.H. The influences of admixtures on the dispersion, workability, and strength of carbon nanotube-OPC paste mixtures. Cem. Concr. Comp. 2012, 34, 201-207. [CrossRef]

21. Konsta-Gdoutos, M.S.; Danoglidis, P.A.; Falara, M.G. Fresh and mechanical properties, and strain sensing of nanomodified cement mortars: The effects of MWCNT aspect ratio, density and fictionalization. Cem. Concr. Compos. 2017, 82, 137-151. [CrossRef]

22. Ma, S.; Qian, Y.; Kawashima, S. Performance-based study on the rheological and hardened properties of blended cement mortars incorporating palygorskite clays and carbon nanotubes. Constr. Build. Mater. 2018, 171, 663-671. [CrossRef]

23. Souza, T.C.; Pinto, G.; Cruz, V.S.; Moura, M.; Ladeira, L.O.; Calixto, J.M. Evaluation of the rheological behavior, hydration process, and mechanical strength of Portland cement pastes produced with carbon nanotubes synthesized directly on clinker. Constr. Build. Mater. 2020, 248, 118686. [CrossRef] 
24. Paula, J.N.; Calixto, J.M.; Ladeira, L.O.; Ludvig, P.; Souza, T.C.C.; Rocha, J.M.; Melo, A.A.V. Mechanical and rheological behavior of oil-well cement slurries produced with clinker containing carbon nanotubes. J. Petrol. Sci. Eng. 2014, 122, 274-279. [CrossRef]

25. Reales, O.A.M.; Jaramillo, Y.P.A.; Botero, J.C.O.; Delgado, C.A.; Quintero, J.H.; Filho, R.D.T. Influence of MWCNT/surfactant dispersions on the rheology of Portland cement pastes. Cem. Concr. Res. 2018, 107, 101-109. [CrossRef]

26. Nadiv, R.; Vasilyev, G.; Shtein, M.; Peled, A.; Zussman, E.; Regev, O. The multiple roles of a dispersant in nanocomposite systems. Compos. Sci. Technol. 2016, 133, 192-199. [CrossRef]

27. Skripkiunas, G.; Karpova, E.; Barauskas, I.; Bendoraitiene, J.; Yakovlev, G. Rheological Properties of Cement Pastes with Multiwalled Carbon Nanotubes. Adv. Mater. Sci. Eng. 2018, 2018, 8963542. [CrossRef]

28. Skripkiunas, G.; Karpova, E.; Bendoraitiene, J.; Barauskas, I. Effect of MWCNT and PCE plasticizer on the properties of cement pastes. IOP Conf. Series Mat. Sci. Eng. 2019, 660, 012032. [CrossRef]

29. Skripkiunas, G.; Karpova, E.; Dauksys, M. Rheological behaviour modelling of cement paste with nanotubes and plasticizer. J. Silic. Based Compos. Mater. 2019, 71, 184-189. [CrossRef]

30. Msinjili, N.S.; Schmidt, W.; Mota, B.; Leinitz, S.; Kuhne, H.C.; Rogge, A. The effect of superplasticizers on rheology and early hydration kinetics of rice husk ash-blended cementitious systems. Constr. Build. Mater. 2017, 150, 511-519. [CrossRef]

31. Chandra, S.; Bjornstrom, J. Influence of superplasticizer type and dosage on the slump loss of Portland cement mortars-Part II. Cem. Concr. Res. 2002, 32, 1613-1619. [CrossRef]

32. Houst, Y.F.; Bowen, P.; Perche, F.; Kauppi, A.; Borget, P.; Galmiche, L.; Meins, J.F.L.; Lafuma, F.; Flatt, R.J.; Schober, I.; et al. Design and function of novel superplasticizers for more durable high performance concrete (superplast project). Cem. Concr. Res. 2008, 38, 1197-1209. [CrossRef]

33. Lu, Z.; Kong, X.; Zhang, C.; Xing, F.; Zhang, Y. Effect of colloidal polymers with different surface properties on the rheological property of fresh cement pastes. Colloids Surf. A Physicochem. Eng. Asp. 2017, 520, 154-165. [CrossRef]

34. Zhang, Y.; Luo, X.; Kong, X.; Wang, F.; Gao, L. Rheological properties and microstructure of fresh cement pastes with varied dispersion media and superplasticizers. Powder Technol. 2018, 330, 219-227. [CrossRef]

35. Guo, Y.; Ma, B.; Zhi, Z.; Tan, H.; Liu, M.; Jian, S.; Guo, Y. Effect of polyacrylic acid emulsion on fluidity of cement paste. Colloids Surf. A 2017, 535, 139-148. [CrossRef]

36. Shrivastava, A.K.; Kumar, M. Compatibility issues of cement with water reducing admixture in concrete. Perspect. Sci. 2016, 8, 290-292. [CrossRef]

37. Uchikawa, H.; Hanehara, S.; Sawaki, D. The role of steric repulsive force in the dispersion of cement particles in fresh paste prepared with organic admixture. Cem. Concr. Res. 1997, 27, 37-50. [CrossRef]

38. Kalliola, A.; Vehmas, T.; Liitia, T.; Tamminen, T. Alkali- $\mathrm{O}_{2}$ oxidized lignin-A bio-based concrete plasticizer. Ind. Crop. Prod. 2015, 74, 150-157. [CrossRef]

39. Huynh, L.; Beattie, D.A.; Fornasiero, D.; Ralston, J. Effect of polyphosphate and naphthalene sulfonate formaldehyde condensate on the rheological properties of dewatered tailings and cemented paste backfill. Miner. Eng. 2006, 19, 28-36. [CrossRef]

40. Yahia, A.; Tanimure, M. Rheology of belite-cement-Effect of w/c and high-range water-reducer type. Constr. Build. Mater. 2015, 88, 169-174. [CrossRef]

41. Qian, Y.; Schutter, G.D. Different effects of NSF and PCE superplasticizer on adsorption, dynamic yield stress and thixotropy of cement pastes. Materials 2018, 11, 695. [CrossRef]

42. Dalas, F.; Pourchet, S.; Nonat, A.; Rinaldi, D.; Sabio, S.; Mosquet, M. Fluidizing efficiency of comb-like superplasticizers: The effect of the anionic function, the side chain length and the grafting degree. Cem. Concr. Res. 2015, 71, 115-123. [CrossRef]

43. Gupta, C.; Sverdlove, M.J.; Washburn, N.R. Molecular architecture requirements for polymer-grafted lignin superplasticizers. Soft Matter 2015, 11, 2691-2699. [CrossRef] [PubMed]

44. Areskogh, D.; Li, J.; Gellerstedt, G.; Henriksson, G. Structural modification of commercial lignosulphonates through laccase catalysis and ozonolysis. Industr. Crops. Prod. 2010, 32, 458-466. [CrossRef]

45. Marchon, D.; Boscaro, F.; Flatt, R.J. First steps to the molecular structure optimization of polycarboxylate ether superplasticizers: Mastering fluidity and retardation. Cem. Concr. Res. 2019, 115, 116-123. [CrossRef] 
46. Qian, S.; Yao, Y.; Wang, Z.; Cui, S.; Liu, X.; Jiang, H.; Guo, Z.; Lai, G.; Xu, Q.; Guan, J. Synthesis, characterization and working mechanism of a novel polycarboxylate superplasticizer for concrete possessing reduced viscosity. Constr. Build. Mater. 2018, 169, 452-461. [CrossRef]

47. Winnefeld, F.; Becker, S.; Pakusch, J.; Gotz, T. Effects of the molecular architecture of comb-shaped superplasticizers on their performance in cementitious systems. Cem. Concr. Comp. 2007, 29, 251-262. [CrossRef]

48. Han, J.; Wang, K. Influence of bleeding on properties and microstructure of fresh and hydrated Portland cement paste. Constr. Build. Mater. 2016, 115, 240-246. [CrossRef]

49. Peng, Y.; Jacobsen, S. Influence of water/cement ratio, admixtures and filler on sedimentation and bleeding of cement paste. Cem. Concr. Res. 2013, 54, 133-142. [CrossRef]

50. MacLeod, A.J.N.; Fehervari, A.; Gates, W.P.; Garcez, E.O.; Aldridge, L.P. Enhancing fresh properties and strength of concrete with a pre-dispersed carbon nanotube liquid admixture. Constr. Build. Mater. 2020, 247, 118524. [CrossRef]

51. Gelardi, G.; Mantellato, S.; Marchon, D.; Palacios, M.; Eberhardt, A.B.; Flatt, R.J. Chemistry of chemical admixtures. In Science and Technology of Concrete Admixtures; Aïtcin, P.C., Flatt, R.J., Eds.; Woodhead Publishing: Kidlington, UK, 2015; pp. 149-171.

52. Skripkiunas, G.; Dauksys, M. Dilatancy of cement slurries with chemical admixtures. J. Civ. Eng. Manag. 2004, 3, 227-233. [CrossRef]

53. Al-Rub, R.K.A.; Ashour, A.; Tyson, B.M. On the aspect ratio effect of multi-walled carbon nanotubes reinforcements on the mechanical properties of cementitious nanocomposites. Constr. Build. Mater. 2012, 35, 647-655. [CrossRef]

54. Collepardi, M. Admixtures used to enhance placing characteristics of concrete. Cem. Concr. Compos. 1998, 20, 103-112. [CrossRef]

55. Yoshioka, K.; Sakai, E.; Daimon, M.; Kitahara, A. Role of steric hindrance in performance of superplasticizers for concrete. J. Am. Ceram. Soc. 1997, 80, 2667-2671. [CrossRef]

56. Chuang, P.H.; Tseng, Y.H.; Fang, Y.; Gui, M.; Ma, X.; Luo, J. Effect of side chain length on polycarboxylate superplasticizer in aqueous solution: A computational study. Polymers 2019, 11, 346. [CrossRef] [PubMed]

57. Wang, Q.; Wang, J.; Lv, C.; Cui, X.; Li, S.; Wang, X. Rheological behavior of fresh cement pastes with a graphene oxide additive. New Carbon Mat. 2016, 31, 574-584. [CrossRef]

58. Nazar, S.; Yang, J.; Thomas, B.S.; Azim, I.; Rehman, S.K.U. Rheological properties of cementitious composites with and without nanomaterials: A comprehensive review. J. Clean. Prod. 2020, 122701. [CrossRef]

59. Leonavicius, D.; Pundiene, I.; Girskas, G.; Pranckeviciene, J.; Kligis, M.; Kairyte, A. The effect of multi-walled carbon nanotubes on the rheological properties and hydration process of cement pastes. Constr. Build. Mater. 2018, 189, 947-954. [CrossRef]

60. Mahaut, F.; Mokeddem, S.; Chateau, X.; Roussel, N.; Ovarlez, G. Effect of coarse particle volume fraction on the yield stress and thixotropy of cementitious materials. Cem. Concr. Res. 2008, 38, 1276-1285. [CrossRef]

61. Li, G.Y.; Wang, P.M.; Zhao, X. Mechanical behavior and microstructure of cement composites incorporating surface-treated multi-walled carbon nanotubes. Carbon 2005, 43, 1239-1245. [CrossRef]

62. Kang, S.-T.; Seo, J.-Y.; Park, S.-H. The characteristics of CNT/Cement Composites with Acid-Treated MWCNTs. Adv. Mat. Sci. Eng. 2015, 308725. [CrossRef]

(C) 2020 by the authors. Licensee MDPI, Basel, Switzerland. This article is an open access article distributed under the terms and conditions of the Creative Commons Attribution (CC BY) license (http://creativecommons.org/licenses/by/4.0/). 